\title{
Expectation Biases and Context Management with Negative Polar Questions
}

\begin{abstract}
Alex Silk ${ }^{1}$
Received: 14 January 2018 / Accepted: 1 April 2019/ Published online: 7 May 2019

(C) The Author(s) 2019
\end{abstract}

\begin{abstract}
This paper examines distinctive discourse properties of preposed negative yes/no questions (NPQs), such as Isn't Jane coming too?. Unlike with other yes/no questions, using an NPQ $\sim p$ ? invariably conveys a bias toward a particular answer, where the polarity of the bias is opposite of the polarity of the question: using the negative question $\sim p$ ? invariably expresses that the speaker previously expected the positive answer $p$ to be correct. A prominent approach- what I call the contextmanagement approach, developed most extensively by Romero and Han (Linguistics and Philosophy, 27, 609-658 2004) — attempts to capture speaker expectation biases by treating NPQs fundamentally as epistemic questions about the proper discourse status of a proposition. I raise challenges for existing context-managing accounts to provide more adequate formalizations of the posited context-managing content, its implementation in the compositional semantics and discourse dynamics, and its role in generating the observed biases. New data regarding discourse differences between NPQs and associated epistemic modal questions are introduced. I argue that we can capture the roles of NPQs in expressing speakers' states of mind and managing the discourse common ground without positing special context-managing operators or treating NPQs as questions directly about the context. I suggest that we treat the operator introduced with preposed negation as having an ordinary semantics of epistemic necessity, though lexically associated with a general kind of endorsing use observed with modal expressions. The expressive and context-managing roles of NPQs are explained in terms of a general kind of discourse-oriented use of context-sensitive language. The distinctive expectation biases and discourse properties observed with NPQs are derived from the proposed semantics and a general principle of Discourse Relevance.
\end{abstract}

Keywords Questions · Negative polar questions · Biased questions · Epistemic modals · Context-sensitivity $\cdot$ Context-managing operators $\cdot$ Expressives ·

Subjective use

Alex Silk

a.silk@bham.ac.uk

1 Department of Philosophy, University of Birmingham, ERI Building, Birmingham, B15 2TT, UK 


\section{Introduction}

This paper examines certain distinctive discourse properties of yes/no questions with preposed negation - negative polar questions (NPQs) — such as (1).

(1) Isn't Jane coming to the party later?

Unlike with positive yes/no questions, uttering an NPQ such as (1) necessarily conveys the speaker's prior expectation that the positive answer is correct (Ladd [33], Büring and Gunlogson [10], Romero and Han [57]) — here, that Jane is coming to the party:

(2) [Context: We're wondering who is coming to the party. A mentions that John is coming. $S$ happens to know that Jane is good friends with John, and so is likely to come. $S$ says:]

a. Isn't Jane coming too?

b. Is Jane coming too?

(Positive speaker expectation)

(3) [Context: We're wondering who is coming to the party. A mentions that John is coming. We have no idea if Jane was invited, if she is friends with John, what her plans are, etc. $S$ says:]

a. \#Isn't Jane coming too?

b. Is Jane coming too?

(Neutral speaker expectation)

(4) [Context: We're wondering who is coming to the party. A mentions that John is coming. $S$ happens to know that Jane has an important competition tomorrow, and so is unlikely to come. $S$ says:]

a. \#Isn't Jane coming too?

b. \#Is Jane coming too?

(Negative speaker expectation)

One can felicitously utter Is Jane coming too? ( $j$ ?) without having a prior expectation about whether Jane is coming; and if one does have an expectation, it is toward the answer whose polarity corresponds to the polarity of the question, i.e. the positive answer $j$ that Jane is coming. By contrast, the polarity of the NPQ Isn't Jane coming too? $(\sim j$ ?) is negative, but using $\sim j$ ? still conveys an expectation toward the positive answer $j$. Indeed, using the NPQ is infelicitous if the speaker is neutral about whether $j$ or would have expected $\neg j$. The challenge is to explain $(a)$ why using an NPQ necessarily conveys an expectation about the correct answer, and $(b)$ why this expectation is toward the positive answer, the answer whose polarity is opposite of the polarity of the question. ${ }^{1}$

\footnotetext{
${ }^{1}$ I use $p, q$, etc. multiply as variables and schematic letters for positive sentence radicals/TPs, and for the possible-worlds propositions they denote (sets of worlds or their characteristic functions). Likewise I use $\neg$ both for clausal negation and in the metalanguage for set complementation. I use $\sim$ for preposed negation when abbreviating NPQs, e.g. $j$ ? for Isn't Jane coming?. I use 'positive/negative answer' for the answer whose polarity is positive/negative; for both positive and negative polar questions, a positive answer is an answer that implies $p$, and a negative answer is an answer that implies $\neg p$. A positive/negative answer, in this sense, may or may not correspond to an answer with a positive/negative polarity particle (yes/no).
} 
A prominent approach-what I will call the context-management approach - attempts to capture the data regarding speaker expectation biases by treating NPQs $\sim p$ ? fundamentally as epistemic questions about the proper discourse status of a proposition $p$ (esp. Romero and Han [57], also Romero [54-56] and Repp [49-51]). Whereas ordinary polar questions are questions about the subject matter of the discourse, NPQs are treated as questions about the discourse itself - roughly put, questions about whether it's certain that $p$ is to be added to the discourse common ground, the body of information taken for granted for purposes of conversation (Stalnaker [72, 73]). Preposed negation contributes a context-managing operator - an operator that directly targets an element of the representation of context. NPQs afford a conventional linguistic means for directly managing the discourse common ground.

This paper critically examines the context-management approach to NPQs. The central aims are threefold: first, to raise empirical and theoretical challenges for previous context-management accounts; second, to provide new data relevant for theorizing about NPQs and biased questions more generally; third, to introduce a novel strategy for capturing distinctive discourse properties of NPQs in an operator-based account. I argue that we can capture the intuitive role of NPQs in managing the context, but without positing special context-managing operators or treating NPQs as fundamentally about the context. The proposed epistemic operator account provides a more empirically adequate, explanatory treatment of the use of NPQs in expressing speakers' states of mind and managing the common ground.

An overview is as follows. Section 2 raises challenges for existing contextmanagement accounts, focusing primarily on Romero and Han [57] ("R\&H"). I begin with worries concerning the technical implementations of the posited contextmanaging operators, and the proposed derivations of speaker expectation biases with NPQs. These worries raise general challenges for any account which analyzes NPQs in terms of context-managing operators. Principal challenges include to explain linguistic and discourse differences between NPQs and associated epistemic modal questions, and between NPQs and recognized devices of attitude-expression and context-management. These differences haven't been observed in previous literature.

The paper's central constructive project is taken up in Section 3. Section 3 argues that we can capture intuitions motivating context-management accounts without positing special context-managing operators or treating NPQs as fundamentally about the context. I suggest that we treat the operator introduced with preposed negation as having an ordinary semantics of epistemic necessity, though lexically associated with a general kind of endorsing use observed with modal expressions. The expressive and context-managing roles of NPQs are explained in terms of an independently attested kind of discourse-oriented use of context-sensitive language (Silk [63, 65, 67]). I show how NPQs' distinctive expectation biases and discourse properties can be derived using two additional independently motivated pieces of apparatus: first, a distinction between a possibility's being compatible with a body of information and its being live; second, a general principle of discourse relevance, generalized from previous literature. The proposed epistemic operator account distinguishes the interpretations of NPQs and associated epistemic modal questions, and predicts their contrasting biases and discourse properties. 
Section 4 concludes and raises several issues for future research. Section $4.1 \mathrm{com}-$ pares the account from Section 3 with alternative speech-act approaches to NPQs. Section 4.2 revisits R\&H's assumption that preposing negation introduces an additional operator, and outlines an alternative implementation which treats preposed negation as itself having a modal semantics. Section 4.3 examines answer patterns with NPQs.

Several remarks on the scope of the discussion are in order. First, I have characterized the bias intuitively associated with NPQs as an expectation that a particular answer is correct. As has been observed, this expectation may be partly normative. Though the speaker in (5) may not have previously thought it likely that the embedded proposition $p$ was true, she still conveys a bias (expectation, preference) toward continuations of the discourse in which $p$ is accepted.

Aren't you ashamed of yourselves?

(Huddleston and Pullum [25, 880, 883-884])

My talk of an "expectation bias" toward a particular answer may be understood broadly to cover cases such as these.

Second, I focus on polar questions with preposed negation - in English, questions of the form $A u x+n$ 't $p$ ?. Questions with non-preposed negation needn't express a prior expectation that the positive answer is correct; they can be unbiased, and they can express a prior expectation in the negative answer $\neg p$ (see n. 1$):^{2}$

(6) [Context: $S$ is interviewing a professional athlete $A$ about $A$ 's training regimen. $S$ has no prior beliefs about $A$ 's schedule/habits. $S$ says:]

Tell us about your training. Do you wake up early?...

a. \#Don't you eat sweets?

b. Do you not eat sweets?

(Neutral speaker expectation)

(7) [Context: $S$ is interviewing a professional athlete $A$ about $A$ 's training regimen. Vegetable and dessert platters are on the table. $S$ thinks it unlikely that $A$ would have sweets during training; indeed, $A$ is having vegetables but no desserts. $S$ says:]

Tell us about your training. I notice you're just eating the vegetables...

a. \#Don't you eat sweets during the season?

b. Do you not eat sweets during the season?

(Negative speaker expectation)

Third, it is common following Ladd [33] to distinguish "outer-negation" and "inner-negation" readings of NPQs — as R\&H put it, readings which "doublecheck" $p$, and readings which "double-check" $\neg p$, respectively. The readings can

\footnotetext{
${ }^{2}$ Romero and Han [57] observe that this contrast between preposed and non-preposed negative polar questions arises across languages. Generally put, the bias associated with NPQs is a bias toward the answer expressed by the material under the preposed negation. I put NPQs with both preposed and non-preposed negation aside. Such questions exhibit the distinctive properties of preposed negative questions but with opposite polarity; for instance, they invariably convey the speaker's prior expectation in the negative answer - e.g., in Isn't Jane not coming?, that Jane is not coming.
} 
be distinguished with positive vs. negative polarity items, and they differ in their constraints on the prior context:

(8) A: John just got here, so we're all ready to go to the party.

$S$ : Isn't Jane coming too? (outer-negation reading)

(9) A: John isn't coming to the party. So no one from our class will be there.

$S$ : Isn't Jane coming either? (inner-negation reading)

Some have argued that inner-negation readings are ordinary questions about whether $\neg p$, and that only outer-negation readings call for a distinctive linguistic representation (Asher and Reese [2], Reese [48]). For this reason I focus exclusively on outer-negation readings - readings in which positive polarity items are licensed. Hereafter by 'NPQ' I will mean "polar question with preposed negation that licenses positive polarity items" (written $\sim p$ ?).

Fourth, NPQs aren't the only questions that seem to "bias" or highlight one answer over others. There are also rising declaratives (questions with declarative syntax and rising prosody; Gunlogson [21, 22], Trinh [85]), incredulity-contour declaratives (questions with declarative syntax and fall-rise prosody; Reese [48], Krifka [31]), and reversed-polarity tag questions (Sadock [60]), among others (see also Malamud and Stephenson [38]). I leave open how the account of NPQs in Section 3 might be extended to other kinds of biased questions.

Fifth, Büring and Gunlogson [10] observe that polar questions are also associated with a "contextual evidence bias": Using a positive polar question $p$ ? is infelicitous if there is (salient, compelling) evidence for $\neg p$ in the discourse context; and using a negative polar question is infelicitous if there is (salient, compelling) evidence for $p$ :

(10) [Context: $A$ enters $S$ 's windowless computer room wearing a dripping wet raincoat. $S$ says:]
a. Is it raining outside?
b. \#Is it sunny outside?
c. \#Is it not raining?
d. \#Isn't it raining?

(cf. Büring and Gunlogson [10, ex. 18])

The polarity of the contextual evidence bias parallels the polarity of the question. What is interesting about the speaker expectation bias is that with NPQs, unlike with positive polarity questions (or non-preposed negative questions), the polarity of the bias is opposite to the polarity of the question. It's this speaker expectation bias - the bias reflecting the speaker's individual prior expectation about the correct answer - that will concern us here.

\section{NPQs and Context-Managing Operators}

This section critically examines previous context-management accounts of NPQs. These accounts agree in understanding NPQs fundamentally as questions about the proper discourse status of a proposition; and they agree in implementing this idea by interpreting NPQs with respect to a context-managing operator - an operator which 
directly targets an element in the representation of the discourse such as the Common Ground (CG). In Romero and Han [57] (also Romero [54, 55]) the operator is treated as a covert operator VERUM contributed by the preposing of negation; in Repp [51] (also Romero [56]) the operator is treated as an operator FALSUM contributed by the negation itself. To fix ideas I focus on the VERUM-based account in Romero and Han [57] $(\mathrm{R} \& \mathrm{H})$, as it provides the most extensive treatment of speaker expectation biases. I return briefly to Repp's FALSUM-based account in Section 2.5.

\subsection{Romero \& Han: VERUM and Bias. Overview}

R\&H hypothesize that VERUM - the putative context-managing operator in the interpretation of NPQs - is also introduced by polarity focus and epistemic really, as in (11)-(12). R\&H's semantics for VERUM is in (13), abbreviated 'FOR-SURE$\mathrm{CG}_{x}$ ' - where $x$ is a variable contextually identified with the speaker/addressee, $C G_{w}$ is the common ground of the conversation in $w, E p i_{x}(w)$ is $x$ 's epistemic alternatives (the set of worlds compatible with what $x$ knows) in $w$, and $\operatorname{Conv}_{x}(w)$ is the set of worlds where all of $x$ 's conversational goals in $w$ are satisfied.

\section{$[\mathrm{IS}]_{F}$ Jane coming?}

\section{Is Jane really coming?}

$$
\begin{aligned}
& \llbracket \operatorname{VERUM}_{i} \rrbracket^{g x / i} \\
& =\lambda p_{s t} . \lambda w_{s} \cdot \forall w^{\prime} \in \operatorname{Epi}_{x}(w): \forall w^{\prime \prime} \in \operatorname{Conv}_{x}\left(w^{\prime}\right): p \in C G_{w^{\prime \prime}} \\
& =\text { FOR-SURE-CG }_{x} \\
& \text { (Romero and Han [57, 627]) }
\end{aligned}
$$

VERUM $_{i} p$ is true, on R\&H's semantics, iff for all of $x$ 's epistemic alternatives $w^{\prime}, p$ is in the discourse common ground in every world $w^{\prime \prime}$ in which all of $x$ 's conversational goals in $w^{\prime}$ are satisfied (n. 1). Informally, "VERUM is used not to assert [ $p$, or] that the speaker is entirely certain about the truth of $p$, but to assert that the speaker is certain that $p$ should be added to the Common Ground (CG)" [57, 627].

$\mathrm{R} \& \mathrm{H}$ posit that the non-canonical syntax of preposing negation introduces VERUM. The denotation for an NPQ $\sim p$ ? thus yields an "epistemically unbalanced" partition between certainty that $p$ should be added to the CG and any other credence that $p$ should be added to the CG, as reflected in (15). A positive polar question $p$ ?, by contrast, yields a "balanced" partition between $p$ and $\neg p$, as in (16). ( $Q$ is the question operator, given a familiar partition semantics such as (14), and $j$ is the proposition that Jane is coming. For convenience I follow R\&H in using both function-based and set-based denotations for questions. I often leave implicit the index $i$ and assignment mapping $i$ to $x$. See n. 1.)

$$
\begin{aligned}
& \llbracket Q \rrbracket=\lambda p_{s t} \cdot \lambda w_{s} \cdot \lambda q_{s t} \cdot q=p \vee q=\neg p \\
& =\lambda p_{s t} \cdot \lambda w_{s} \cdot\{p, \neg p\} \\
& =\lambda q \cdot q=\text { FOR-SURE-CG }_{x} j \vee q=\neg \text { FOR-SURE-CG }{ }_{x} j \\
& =\left\{\text { FOR-SURE-CG }{ }_{x} j, \neg \text { FOR-SURE-CG }{ }_{x} j\right\}
\end{aligned}
$$




$$
\begin{aligned}
& \text { a. Is Jane coming? } \\
& \text { b. LF: [ } Q \text { [Jane is coming]] } \\
& \text { c. } \llbracket(16 \mathrm{~b}) \rrbracket\left(w_{0}\right) \\
& =\lambda q \cdot q=j \vee q=\neg j \\
& =\{j, \neg j\}
\end{aligned}
$$

$\mathrm{R} \& \mathrm{H}$ explain speaker expectation biases with NPQs $\sim p$ ? in two stages. First, the existence of an expectation bias is explained as a (non-cancellable) implicature arising from (i) the epistemically unbalanced partition generated by VERUM about the discourse move of adding $p$ to the CG, and (ii) a posited (non-violable) pragmatic principle, (17), governing discourse moves about other discourse moves ("meta-conversational moves") (cf. [57, 609n.1]).

\section{Principle of Economy: \\ Do not use a meta-conversational move [i.e., context-managing operator] unless necessary (to resolve epistemic conflict or to ensure Quality). [57, 629]}

By R\&H's Principle of Economy, uttering an NPQ $\sim p$ ? is felicitous only if the speaker has reason to question whether $p$ should be added to the $\mathrm{CG}-\mathrm{e}$.g., if the speaker disagrees with a previous assertion about whether $p$ (to resolve epistemic conflict), or if the speaker has views about whether $p$ but lacks sufficient grounds to assert it (to avoid violating the Maxim of Quality). R\&H conclude that a cooperative speaker will use an NPQ only if she has a prior epistemic bias about $p .^{3}$

Next, R\&H explain the positive polarity of the expectation bias - the bias toward the positive answer - by invoking the notion of a question's "intent." Following Bolinger [7], R\&H observe that a request for help can be made by asking the positive polar question in (18a), but not by asking the negative polar question in (18b) or the alternative question in (18c).

\section{Request for help:}
a. Will you please help me?
b. \#Will you please not help me?
c. \#Will you please help me or not?

(Bolinger [7, 89]; Romero and Han [57, 642])

Though $\mathrm{R} \& \mathrm{H}$ don't provide a formal account of intent, the intuitive idea is that the "pronounced cell" of a polar question - the cell expressed by the question radical — sets the "topic" and reflects which proposition "the speaker is interested in

\footnotetext{
3"Why is the unbalanced partition ... inappropriate in contexts with no previous bias? The unbalanced partition would violate the Principle of Economy in [(17)]. For if the addressee uttered $p$ or $\neg p$, the unbiased speaker would have no reason not to execute the instruction of adding $p$ or $\neg p$ to the CG... and hence the meta-conversational move [invoking an unbalanced partition] would be unjustified. Similarly ..., if $p$ was relevant to the conversation but the speaker was completely unbiased between $p$ or $\neg p$, the balanced partition would be more economical and the unbalanced partition unmotivated" (Romero and Han $[57,629])$.
} 
pursuing a conversation about" (Romero and Han [57, 642]). ${ }^{4}$ The "intent" of a polar question, for R\&H's purposes, is treated as the combination of the partition denotation and which cell is pronounced, as in (19).

$$
\begin{aligned}
& \text { “Intent" (denotation and pronounced cell) for } \sim p ? \\
& \left\{\text { FOR-SURE-CG }{ }_{x} p, \neg \text { FOR-SURE-CG }{ }_{x} p\right\}
\end{aligned}
$$

The explanation of the bias toward the positive answer proceeds roughly as follows. (A more detailed reconstruction is given in Section 2.4.) In uttering $\sim p$ ? the speaker pronounces the cell $\neg$ FOR-SURE-CG $x$ p of the question's denotation. Pronouncing the cell $\neg$ FOR-SURE-CG ${ }_{x} p$ constitutes a request for possible grounds for doubting $p$. Such a request would be infelicitous if the speaker was biased toward $\neg p$; after all, if the speaker expected $\neg p$, she would already have reasons to doubt $p$. So, in pronouncing the cell $\neg$ FOR-SURE-CG $x p$, the speaker "suggest[s] that $p$ be added to the Common Ground unless the addressee has reasons to doubt $p$ " (Romero and Han [57, 649]). Such a suggestion would be infelicitous if the speaker antecedently expected $\neg p$, but felicitous if the speaker antecedently expected $p$. So, since an NPQ is felicitous only if the speaker has some epistemic bias about $p$ (as explained above), this bias must be toward accepting the positive answer $p$. Or so $\mathrm{R} \& \mathrm{H}$ argue.

\subsection{VERUM and Epistemic Predicates}

The guiding intuition behind the context-management approach is that NPQs $\sim p$ ? question the appropriateness of a certain discourse move: adding $p$ to the CG. The following subsections raise worries for R\&H's way of capturing this idea. I begin with concerns about details of R\&H's implementation, followed by general challenges for context-management accounts.

R\&H observe that VERUM cannot be used interchangeably with "pure epistemic expressions" (Romero and Han [57, 626]) such as be sure:

(20) [Context: $S$ is a lawyer questioning a witness, $A$, who claims to have seen Mrs. Rumpel the night of the crime. $S$ wants to check $A$ 's degree of certainty about this, but without conveying disbelief. $S$ asks:]

a. Are you sure that you saw Mrs. Rumpel leave the house that night?

b. \#Did you really see Mrs. Rumpel leave the house that night?

c. \#Didn't you not see Mrs. Rumpel leave the house that night?

(Romero and Han [57, 626])

R\&H's semantics obscures such contrasts. Given common assumptions about information-sharing discourse, R\&H's formalization predicts that $\operatorname{VERUM}_{i} p$ and $i$ knows $p$ are contextually equivalent in their truth-conditions.

According to (13), $\operatorname{VERUM}_{i} p$ is true iff for all worlds $w^{\prime}$ in $x$ 's epistemic alternatives, $p$ is included in the CG in every world $w^{\prime \prime}$ in which all of $x$ 's conversational

\footnotetext{
${ }^{4}$ See van Rooy and Šafářová [58] for a decision-theoretic account which treats the pronounced cell as the cell with greater conversational utility.
} 
goals in $w^{\prime}$ are satisfied. A primary overarching goal of inquiry is to figure out how things are - formally, to winnow down the context set CS (the set of worlds where all the propositions in the CG are true) to a singleton set $\{w @\}$ of the actual world (Stalnaker [73], Roberts [52]). Let a transparent context be one in which the speakers know that they are engaged in a cooperative information-sharing discourse and know their discourse goals; and assume that if one knows $p$, then one knows that one knows $p$ - or, what may be weaker, that if one knows $p$, then one knows that one bears $R$ to $p$, where $R$ is whatever attitude suffices for ensuring Quality (knowledge, justified belief, etc.) ("introspection"). Then:

Proposition 1 For any transparent context $c, \operatorname{VERUM}_{i} p$ is true in $c$ (according to (13)) iff $i$ knows $p$ is true in $c$

For the left-to-right direction: Given transparency, for any $w^{\prime}$ in $x$ 's epistemic alternatives and proposition $q$, if $q \in C G_{w^{\prime \prime}}$ for every $w^{\prime \prime} \in \operatorname{Conv}_{x}\left(w^{\prime}\right)$, then $q$ must be true at $w^{\prime}$. For if $q$ is false at $w^{\prime}$, then $q \notin C G_{w^{\prime \prime}}$ for any $w^{\prime \prime} \in \operatorname{Con}_{x}\left(w^{\prime}\right)$, since a discourse goal in $w^{\prime}$ is to avoid adding falsehoods to the CG. So, if $\operatorname{VERUM}_{i} p$ is true, then $p$ must be true at every world $w^{\prime}$ in $x$ 's epistemic alternatives, i.e. $i$ knows $p$ is true. For the right-to-left direction: Suppose $i$ knows $p$ is true, so $p$ is true at every $w^{\prime}$ in $x$ 's epistemic alternatives. Given introspection, $x$ knows that $x$ bears $R$ to $p$, hence $x$ bears $R$ to $p$ in every such $w^{\prime}$. So, given transparency, $p$ is in the CG in every world where all of $x$ 's discourse goals in $w^{\prime}$ are satisfied. So, $\operatorname{VERUM}_{i} p$ is true. Putting these points together: for any world in the context set, $\operatorname{VERUM}_{i} p$ is true iff $i$ knows $p$ is true. This obscures R\&H's claim that VERUM is a distinctive context-oriented operator.

One might reply that, common idealizations notwithstanding, "transparent" contexts aren't typical among actual discourses. Recall that R\&H identify $x$ "with the addressee (or with the individual sum of the addressee and the speaker)" [57, 626]. If the addressee has private information/knowledge that she wishes not to share, transparency won't hold. I leave the point as a challenge: to provide a more adequate discourse framework or lexical entry for context-managing operators which clearly distinguishes the interpretations of VERUM and ordinary epistemic attitude predicates. In Section 3 I argue that we can capture the motivations for R\&Hs (13) without treating VERUM as a context-managing operator in the sense of Section 2.0.

\subsection{VERUM and Expressive Content}

One strategy for distinguishing the contextual effects of context-managing operators would be to treat them as having some non-truth-conditional aspect of meaning. Although R\&H don't consider such a move, Repp [49-51] and Romero [54-56] motivate their accounts by exploiting apparent similarities between the posited contextmanaging operators and recognized expressive/discourse-oriented devices - devices which "have been argued to contribute not to the propositional content in the standard way, but to the expressive meaning" (Romero [55]), including discourse particles, epithets, speaker-oriented adverbs (e.g. Potts [46, 47], Gutzmann [23]). For instance, Romero claims that really patterns with linguistic expressives (i) in not contributing 
to local truth-conditional content, as in (21)-(22) compared with obviously, and (ii) in allowing direct affirmations/denials to target the embedded proposition, as in (23)-(24) compared with unfortunately.

(21) [Context: John and Mary made the deal that they would pretend to be in love. In reality, they do not love each other nor care about each other's love.]

a. John is upset because it is obvious that Mary doesn't love him. (true)

b. \#John is upset because obviously Mary doesn't love him. (false)

(22) Kate didn't show up because she really couldn't make it.

(23) A: John, unfortunately, lost the election.

$S: \quad$ That's not true.

$\Rightarrow \neg($ John lost)

* $\neg$ (it is unfortunate that John lost)

(24) A: This professor really is very smart.

$S: \quad$ That's not true.

(Romero [55, exs. 39-41, 43])

Romero [54-56] appeals to such similarities to explain why answers to reallyquestions and NPQs $\sim p$ ? seem to target the embedded proposition $p$, rather than the context-oriented propositions $(\neg)$ FOR-SURE-CG ${ }_{x} p$ which provide the predicted meaning of the question.

$$
\begin{array}{ll}
S: & \text { Did Mary really visit Sue? } \\
A: & \text { Yes }(\ldots, \text { she did }) . \\
A^{\prime}: & \text { No }(\ldots, \text { she didn't }) . \\
S: & \text { Didn't Mary visit Sue? } \\
A: & \text { Yes }(\ldots, \text { she did }) . \\
A^{\prime}: & \text { No }(\ldots, \text { she didn't }) .
\end{array}
$$

(Romero [55, ex. 34])

Formally, Romero allocates expressive/context-managing content to a separate dimension of meaning, reflected in the revised lexical entry for VERUM in (27). The contribution of the question morpheme $Q$ is assumed to be reproduced in both dimensions, per (28), yielding the revised meaning for VERUM-questions in (29). ${ }^{5}$

$$
\begin{aligned}
& \text { a. truth-conditional content: } \llbracket \text { VERUM } \rrbracket=\lambda p_{s t} \cdot p \\
& \text { b. context-managing content: } \llbracket \text { VERUM } \rrbracket_{C M}=\lambda p_{s t} . \text { FOR-SURE-CG }{ }_{x} p \\
& \text { a. truth-conditional content: } \llbracket Q \rrbracket=\lambda p_{s t} \cdot\{p, \neg p\} \\
& \text { b. context-managing content: } \llbracket Q \rrbracket_{C M}=\lambda p_{s t} \cdot\{p, \neg p\} \\
& \text { really } q \text { ? }
\end{aligned}
$$$$
\text { a. } \llbracket Q[\operatorname{VERUM} q] \rrbracket=\{q, \neg q\}
$$

\footnotetext{
${ }^{5}$ I use $\llbracket \cdot \rrbracket$ for expressions' truth-conditional content (Romero's “at-issue content”), and $\llbracket \cdot \rrbracket_{C M}$ for expressions' context-managing content. I follow Romero in grouping non-truth-conditional meanings associated with expressives and context-managing operators under a general heading of "context-managing content." I return to answer patterns in Section 4.3.
} 


\section{b. $\llbracket Q[\operatorname{VERUM} q] \rrbracket_{C M}=\left\{\right.$ FOR-SURE-CG ${ }_{x} q, \neg$ FOR-SURE-CG $\left.{ }_{x} q\right\}$ (adapting Romero [56, exs. 23, 26, 33])}

So, assuming that answer particles target truth-conditional content, the yes/noanswers in (25) are predicted to target the embedded proposition that Mary visited Sue, which constitutes the truth-conditional content of the complement of $Q$.

Central to Romero's [56] revised account are the assumptions that contextmanaging content is targeted by "illocutionary operators," such as $Q$, and not by truth-conditional operators. The former generalization is invoked in explaining speaker expectation biases, which are sensitive to the context-managing content; the latter generalization is invoked in explaining answer patterns, which are not. Both generalizations are problematic. First, there are cases where context-managing content contributes to local truth-conditional content. In (30) $S$ 's contingency planning about whether to take the umbrella doesn't depend on the fact of whether it will rain, but on the subjective possibility of rain; the contributions of epistemic really and maybe/perhaps figure in characterizing the hypothetical scenarios entertained with $S$ 's conditionals. In (31) the expectation biases associated with VERUM — which Romero derives from the context-managing content-are commitments of the attitude subject.

(30) S: I wonder how the weather will be at the game. I hate getting caught without an umbrella.

A: It looks fine out, at least for now. And I don't want to lug that thing around for no reason.

$S: \quad$ If it's really not going to rain, I won't take the umbrella. But if maybe/perhaps it will, let's take it just in case.

(31) a. John wondered whether Jane was really coming to the party.

b. John wondered whether Jane wasn't coming to the party too.

In contrast, the context-managing content of linguistic expressives typically projects and fails to have local effect, as in (32)-(34) (e.g. Potts [46, 47], Tonhauser et al. [83]). The negative attitude associated with that bastard in (32) would typically be attributed to the speaker and not to the subject. (33) isn't questioning whether Kresge is a jerk, whether one dislikes Kresge, etc.

(32) Sue believes that bastard Kresge should be fired. (\#I think he's a good guy.) (Potts [47, ex. 10])

Should that bastard Kresge be fired?

Everyone else loves Kresge. If that bastard gets promoted, I'll quit.

Suppose for simplicity that the context-managing content of that bastard Kresge should be fired is that one dislikes Kresge, abbreviated NEG(K). The observed context-managing content of (33) isn't $\{\mathrm{NEG}(\mathrm{K}), \neg \mathrm{NEG}(\mathrm{K})\}$ as predicted by Romero's semantics, but NEG(K). Contrary to (28), it isn't in general the case that context-managing content embeds under the question operator $Q$.

The contrasts between VERUM and linguistic expressives in projection behavior and local effects are unexpected if their (alleged) context-managing contents 
are implemented in the same kind of way. As in Section 2.2, the worry needn't be devastating. Although Romero assimilates the non-truth-conditional contributions of VERUM, epistemic adverbs, discourse particles, etc. under a heading of "contextmanaging content," there may be reasons to distinguish them in ways relevant to the compositional semantics (cf. Tonhauser et al. [83], Gutzmann [23]). The challenge remains: to implement the alleged context-managing contribution of (e.g.) VERUM in a more adequate formal semantics, and to do so in a way that captures relevant similarities and differences with recognized expressive/discourse-oriented devices.

We should be cautious in assigning theoretical significance to intuitions about attitude-expression and context-management. The neophyte might wonder: "Don't all speech-acts express speakers' (epistemic) attitudes - not just about the world, but about the context, one's interlocutors, and how the discourse should evolve? ${ }^{6}$ Given any plausible norm of assertion (Brown and Cappelen [9]) and force rule (semantic or pragmatic), even a simple assertion that $p$ characteristically expresses the speaker's belief that $p$, the speaker's assumption that $p$ is news to the addressee, the speaker's goal of adding $p$ to the CG, etc. (cf. Stalnaker [73]). If foundational expressivism in philosophy of language is correct, then the meaning of all language, even descriptive language, is to be explained fundamentally in terms of speakers' states of mind (e.g. Gibbard [19, 20], Silk [64]). If we aren't assuming markers for attitude-expression/context-management in the structure of sentences generally, why then with really or NPQs?" There are of course empirical grounds for distinguishing the expressive/context-managing roles of certain constructions - e.g., regarding projection, effects on local content, and embedding behavior, as above. But, adapting a point from Partee and Borschev [44, 72, 103], "we cannot use 'intuitions' of [expressivity/context-management] as a good guide to whether something is "really', a linguistic expressive, in the sense of an expression with a distinctive category of projective content. Absent clear confirming evidence with respect to established diagnostics, it's worth reexamining whether NPQs' apparent expressive/contextmanaging roles might be derived from more general features of context and linguistic acts (Section 3).

\subsection{NPQs, Epistemic Questions, and "Intent"}

This section examines more closely R\&H's derivation of speaker expectation biases with NPQs - R\&H's derivation of how using an NPQ $\sim p$ ? invariably conveys that the speaker previously expected the positive answer $p$ to be correct. Recall that central to R\&H's explanation is the notion of a question's "intent," as determined by the question's partition denotation and which cell in the partition is pronounced. It is

\footnotetext{
${ }^{6} \mathrm{Cf}$. "Discourse particles in the narrow sense are used in order to organize the discourse by expressing the speaker's epistemic attitude towards the propositional content of an utterance, or to express a speaker's assumptions about the epistemic states of his or her interlocutors concerning a particular proposition" (Zimmermann [94, 2012], emphasis added; cf. Repp [51, 231, 240]).
} 
worth quoting R\&H's account of the intent of an NPQ $\sim p$ ?, and how it generates the bias toward the positive answer, largely in full:

Since the pronounced cell is the $\neg$ FOR-SURE-CG C $_{x} p$ cell, the intent of the question is concerned with pursuing the topic "lack of complete certainty about $p$ " or "possible (weak or strong) doubts about $p$ "... Since the intent of the question is to ask the addressee to provide reasons - if any — to doubt $p, \ldots p$ must be the original belief of the speaker, not vice-versa. If, contrary to fact, the speaker believed $\neg p$ to a high degree, the speaker would already have evidence to doubt $p$... Therefore, [NPQs $\sim p$ ?] have the positive epistemic implicature that the speaker believed $p$.

The "intent" of the question is to suggest that $p$ be added to the Common Ground unless the addressee has reasons to doubt $p$. This is a licit suggestion if the speaker endorses $p \ldots$ but it violates the spirit of the Maxim of Quality if the speaker believes $\neg p$.

(Romero and Han [57, 646-647, 649])

One way of reconstructing R\&H's argument in these passages is as follows:

i. $\quad$ Pronouncing the cell $\neg$ FOR-SURE-CG C $_{x} p$ constitutes a request for grounds for doubting $p$.

ii. Requesting grounds for doubting $p$ would be contrary to one's conversational goals (e.g. contrary to Quantity or Quality), hence infelicitous, if one initially expected $\neg p$.

iii. Using a question with an epistemically unbalanced partition would be contrary to the Principle of Economy (17), hence infelicitous, if one was neutral about whether $p$.

iv. So, using an NPQ $\sim p$ ?, pronouncing the cell $\neg$ FOR-SURE-CG ${ }_{x} p$, is felicitous only if the speaker initially expected $p$. So, assuming the speaker is cooperative, using an NPQ invariably conveys that the speaker had a prior expectation toward $p$.

Premise (i) represents the assumption about the intent of an NPQ $\sim p$ ?. The crucial claim is (ii): that requesting grounds for doubting $p$ is infelicitous if one antecedently expected $\neg p .^{7}$ Since the speaker must have some prior epistemic bias about $p$, as per

\footnotetext{
${ }^{7}$ I am not sure what exactly R\&H's grounds are for (ii). The quoted passages suggest two lines of thought:
}

ii-a. If one initially expected $\neg p$, then one already has grounds for doubting $p$. So, requesting grounds for doubting $p$ would be contrary to the spirit of Quantity, hence infelicitous.

ii-b. In requesting grounds for doubting $p$ one "suggest[s] that $p$ be added to the Common Ground unless the addressee has reasons to doubt $p$." Such a suggestion would be contrary to the spirit of Quality, hence infelicitous, if one initially expected $\neg p$.

(ii-b) takes as basic that requesting grounds for doubting $p$ constitutes a defeasible suggestion that $p$ be added to the CG, whereas (ii-a) treats this as an implication of the independently derived positive speaker expectation bias. We will see reasons for questioning both lines of support for (ii). 
(iii) established by R\&H's economy-based argument (Section 2.1), using an NPQ is felicitous only if the speaker expected $p$. So, the argument concludes in (iv), NPQs invariably carry a positive speaker expectation bias.

For the sake of argument I grant R\&H's assumption in (i) about the nature of the act performed in pronouncing the cell $\neg$ FOR-SURE-CG $\mathrm{C}_{x} p$ with an NPQ $\sim p ?^{8}{ }^{8}$ Start with (iii), that NPQ LFs "give rise to unbalanced partitions, hence to epistemic biases" (Romero [55, 12], emphasis added, [54, 3]; see also n. 3). Pace R\&H, using a question with an epistemically unbalanced partition is insufficient for conveying an epistemic bias. S's question Really heads? in (36) has the unbalanced partition \{FOR-SURE-CG ${ }_{x}$ heads, $\neg$ FOR-SURE-CG C $_{x}$ heads\}; yet $S$ gives equal credence to heads and $\neg$ heads.

[Context: $A$ and $S$ are wondering whether to take a bet on a coin toss.]

A: I think the next coin flip will be heads. Let's take the bet.

$S$ : Is it really going to be heads? I think the coin is fair. I don't think we should take the bet.

(Unbalanced partition; No speaker expectation bias)

The epistemic possibility questions in (37) involve a choice between "a fine degree of certainty" — certainty against $p$ — and "any other degree of certainty" (Romero and Han $[57,633,628])$; yet the questions needn't convey that the speaker was expecting a particular answer.

(37) [Context (=(3)): We're wondering who is coming to the party. A says John is coming. We have no idea if Jane was invited, if she's friends with John, what her plans are, etc. $S$ says:]

a. Maybe/Perhaps/Possibly Jane is coming too?

b. Might Jane be coming too?

(Unbalanced partition; No speaker expectation bias)

It cannot be simply an epistemically unbalanced partition which explains that NPQs invariably convey a speaker expectation bias.

Turn to (ii). Pace R\&H, there needn't be anything infelicitous in requesting reasons for doubting a proposition $p$ which one doubts oneself, or even expects is false. Questions with epistemic possibility modals often have precisely this function.

A: The butler is surely the killer.

$S$ : But he has always seemed like such a nice guy. Might/Could it have been someone else? (/Was it perhaps someone else?) Maybe the gardener?

$S$ asks whether someone other than the butler might be the killer, and raises the possibility that it was the gardener. $S$ requests to pursue grounds for doubting that

\footnotetext{
${ }^{8}$ Strictly speaking the intent of the NPQ with pronounced cell $\neg$ FOR-SURE-CG $x p$ should be glossed as a request for grounds for doubting whether $p$ should be added to the $\mathrm{CG}$, rather than as a request for grounds for doubting $p$. I ignore any differences between these acts.
} 
the butler is the killer precisely to express her prior expectation that the butler is not the killer.

It is important to be clear about the dialectical import of the examples with epistemic modal questions. R\&H's claim in (ii) is a claim about the nature of the act of requesting grounds for doubting a proposition $p$. There are various conventional and non-conventional ways of performing such an act. One way, in some contexts, is by uttering $\diamond \neg p$ ? (for some expression of epistemic possibility $\diamond$ ). The act of requesting reasons for doubting a proposition $p$ is compatible with merely having some credence in $p$ or expecting that $p$ would be false.

Epistemic possibility questions also raise worries for the inference to (iv) regarding the strength of the epistemic bias observed with NPQs. One may ask to examine evidence against $p$ because one has some credence in $p$ but one doesn't want the possibility that $\neg p$ to be hastily dismissed:

Moore: My hands hurt.

Skeptic: Do we know you have hands? Maybe you don't have hands and you're just a brain in a vat?

Fred: $\quad$ God is dead.

Blaise: I too find theism hard to believe. But might God exist? Perhaps God isn't dead and is testing our faith?

In (40) Blaise isn't prepared to rule out that they might ultimately have reason to accept that God exists. In (39) Skeptic asks Maybe you don't have hands? ( $\neg$ $\neg$ ?), requesting reasons for doubting $h$. Skeptic might intend to "pursu[e] the topic 'lack of complete certainty about $[h]$ '" because she is committed and expects $\neg h$, or is aporetic and neither expects $h$ nor expects $\neg h$. Or she might simply be an earnest epistemology student wanting to ensure that $\neg h$ isn't improperly ignored.

The challenge raised by epistemic modal questions can be pressed further. Though the details of formal implementation are controversial, all parties agree that a principal use of epistemic modal expressions is to manage the set of live possibilities. ${ }^{9}$ In such a use, accepting $\diamond \neg p$ (e.g. perhaps $\neg p$ ) ensures that the CG is compatible with $\neg p$. Perhaps conventionally, perhaps non-conventionally, asking an epistemic possibility question ("EPQ") $\diamond \neg p$ ? delineates possible continuations of the discourse in which $\neg p$ is live and possible continuations in which $\neg p$ is ruled out, and highlights the former possibilities. These effects are the same effects conventionally associated with $\sim p$ ? on R\&H's semantics and notion of intent. Yet the NPQ $\sim p$ ? and EPQ $\diamond \neg p$ ? have opposite biases and discourse functions. Unlike the NPQ, the EPQ cannot be used to disagree with a prior implication that $\neg p$ (reflected in (41)), or to suggest $p$ as an answer to a relevant question (reflected in (42); cf. Romero and Han [57, ex. 27]).

$$
\begin{aligned}
& \text { A: The butler is surely the killer. } \\
& S: \quad \text { Wasn't it the gardener? }
\end{aligned}
$$$$
\begin{array}{r}
(\Rightarrow \neg \text { gardener }) \\
\text { Aux }+n \text { 't gardener? }
\end{array}
$$

\footnotetext{
${ }^{9}$ For alternative contextualist, relativist, expressivist, and dynamic approaches to capturing this function of epistemic modals, see Veltman [88], Stephenson [77], Yalcin [92], MacFarlane [37], Silk [65], Swanson [80]. I use 'epistemic modal' broadly for expressions of various categories notionally expressing epistemic modality.
} 
$S^{\prime}$ : \#Was it maybe/possibly/perhaps not the gardener? (/Might/Could it have been someone other than the gardener?) $\# \triangleright \neg$ gardener?

(42) [Context: Dialog between two editors of a journal in 1900:]

A: I'd like to send this paper out to a senior reviewer, but I'd prefer somebody who has experience with our regulations.

$S$ : Hasn't Frege reviewed for us? He'd be a good one.

$S^{\prime}$ : \#Maybe/Possibly/Perhaps Frege hasn't reviewed for us? He'd be a good one.

The act of requesting reasons for doubting $p$ can express a prior expectation against $p$, and suggest that $p$ not be added to the CG. ${ }^{10}$

\subsection{Repp: FALSUM}

The foregoing challenges carry over to the FALSUM-based context-management account of NPQs developed by Repp [49-51] (also Romero [56]). Since Repp's focus isn't on speaker expectation biases, I present the view only briefly.

$\mathrm{R} \& \mathrm{H}$ treat the preposing of negation as introducing an additional operator, VERUM, which interacts with negation. In Repp's account, preposed negation is itself a context-managing operator: FALSUM.

$$
\begin{aligned}
& \llbracket \text { FALSUM }_{i} \rrbracket^{g x / i} \\
& \quad=\lambda p_{s t} \cdot \lambda w_{s} \cdot \forall w^{\prime} \in \operatorname{Epi}_{x}(w): \forall w^{\prime \prime} \in \operatorname{Conv}_{x}\left(w^{\prime}\right): p \notin C G_{w^{\prime \prime}} \\
& \quad=\text { FOR-SURE-NOT-CG } \\
&
\end{aligned}
$$
a. Isn't Jane coming (too)?
b. LF: [ $Q$ [FALSUM [Jane is coming (too)]]]
c. $\llbracket(44 \mathrm{~b}) \rrbracket\left(w_{o}\right)=\left\{\right.$ FOR-SURE-NOT-CG ${ }_{x} j, \neg$ FOR-SURE-NOT-CG $\left.{ }_{x} j\right\}$

Roughly put, FALSUM $p$ expresses certainty that $p$ shouldn't be added to the CG. In using an NPQ $\sim p$ ?,

the speaker conveys a previous epistemic bias towards $p$ and wishes to doublecheck that $p$ is part of the CG. This is done by using FALSUM... [T] he addressee is expected to determine whether or not there are zero degrees of strength for adding $p$ to CG. (Repp [51, 243, 240])

the speaker wonders... whether the addressee has fully convincing evidence for not adding $p$ to the $\mathrm{CG}$, suggesting that the speaker is biased towards $p$ and would need strong evidence to be convinced that $p$ should not be added to CG. (Romero [56, 508])

\footnotetext{
${ }^{10}$ The worry is vivid for epistemic possibility expressions whose context-managing use is invariable, analogous to epistemic really, e.g. perhaps (Ernst [13, 515n.14]). For other expressions of epistemic possibility, all parties agree that many can have intuitively expressive/context-oriented uses with discourse and embedding properties like those attributed to really (e.g. von Fintel [15], Papafragou [43], Ernst [13]). On such uses, the "intents" of the NPQ and EPQ are predicted to be equivalent.
} 
Repp doesn't say why using a question with the denotation in (44) amounts to "double-checking $p$," or why double-checking $p$ conveys a "previous epistemic bias towards $p$.” Perhaps Repp might follow R\&H's appeal to intent. However, observe that the pronounced cell in (44) (FOR-SURE-NOT-CG $j$ ) is stronger than the pronounced cell in R\&H's denotation in (15) ( $\neg$ FOR-SURE-CG $j$ ). The predicted intent of $\sim p$ ? would be to pursue conclusive evidence against $p$. It's unclear why requesting conclusive evidence against $p$ (or against adding $p$ to the CG) would necessarily convey an expectation that $p$ (cf. (ii) in (35)). One might expect $\neg p$ but wish to ensure that the possibility that $p$ isn't hastily dismissed, as in (45).

[Context: A dialogue between Moore $(M)$ and a reluctant anti-skeptic $(R)$ ]

$M$ : Of course you have hands!

$R:$ Am I obviously/really/surely not a brain-in-a-vat? It's hard to deny that I have hands, but do we have conclusive reasons for rejecting the skeptic's arguments? Can we rule out the possibility that my apparent experiences as if I have hands are the results of neuroscientists stimulating my brain?

It's felicitous for the reluctant anti-skeptic to request conclusive evidence against the hypothesis $B I V$ that she is a handless brain-in-a-vat even though she is epistemically biased against the hypothesis and expects $\neg B I V .^{11}$

\subsection{Recap}

Let's recap. Using an NPQ $\sim p$ ? invariably conveys that one previously expected the positive answer $p$ to be correct. Context-management accounts attempt to capture this "speaker expectation bias" by treating NPQs fundamentally as questions about the proper discourse status of a proposition; NPQs are interpreted with respect to an operator that directly targets a parameter in the representation of the discourse context. This section has raised challenges to provide more adequate accounts of the posited operator's context-managing content and its implementation in the compositional semantics and discourse dynamics - accounts that capture relevant linguistic and discourse differences with other broadly epistemic, expressive, and context-oriented devices.

In R\&H's account of speaker expectation biases with NPQs, the existence of a bias is derived from the speaker's use of a question with an "epistemically unbalanced" partition denotation; the bias's positive polarity is derived from the nature of the type of act performed in pronouncing the cell $\neg$ FOR-SURE-CG ${ }_{x} p$ in the partition. We have seen reasons to question both moves: Contrary to claim (iii) in (35),

\footnotetext{
${ }^{11}$ Really not questions are especially puzzling for FALSUM-based analyses of NPQs. The predicted intents of Really $\neg p$ ? and $\sim p$ ? are nearly equivalent, as reflected in (i) in comparison to (44) (i.e., pursuing certainty about adding $\neg p$ to CG vs. pursuing certainty about not adding $p$ to CG, the latter in principle allowing for settled agnosticism). Yet the really not question needn't convey a prior expectation in the positive answer. (We will return to this in Section 3.4.)
}

(i) a. Is Jane really/obviously/surely not coming? (= $Q$ [VERUM $\neg j])$

b. $\quad\left\{\right.$ FOR-SURE-CG ${ }_{x} \neg j, \neg$ FOR-SURE-CG $\left.{ }_{x} \neg j\right\}$ 
using a question with an epistemically unbalanced partition can be felicitous even if one is neutral about the embedded proposition (cf. (36)-(37)); contrary to claim (ii), requesting grounds for doubting a proposition $p$ can be compatible with one's conversational goals even if one expects $\neg p$ (cf. (38)). Performing an act of the type claimed to be conventionally performed in using an NPQ can be appropriate while lacking a positive expectation that $p-$ e.g., while being neutral about $p$, being biased toward $\neg p$, or having higher credence in $p$ yet wishing to leave open the possibility that $\neg p$ (also (39)). The data with epistemic possibility questions present a general challenge for broadly epistemic accounts: The NPQ $\sim p$ ? and EPQ $\diamond \neg p$ ? present roughly the same possibilities for how the discourse might evolve, and highlight roughly the same possible continuation of the discourse; yet they express contrasting attitudes and have contrasting discourse functions (cf. (41)-(42)).

\section{Deriving Context-Management and Expectation Biases with NPQs}

A key insight in R\&Hs discussion is that "really or VERUM is used not to assert that the speaker is entirely certain about the truth of $p$, but to assert that the speaker is certain that $p$ should be added to the Common Ground" [57, 627]. This section argues that we can capture the roles of NPQs in expressing speaker attitudes and managing the discourse common ground without giving an element such as VERUM the semantics of an epistemic modal about the context itself. To fix ideas I follow R\&H in assuming that preposing negation introduces an additional operator, VERUM. ${ }^{12}$ However, I suggest that we treat VERUM as having an ordinary semantics of epistemic necessity, though conventionally associated with a general kind of speaker-endorsing, discourse-oriented use of context-sensitive language. The proposed epistemic operator account elucidates the role of VERUM in coordinating speakers' epistemic attitudes, captures relevant similarities and differences among VERUM and categories of epistemic vocabulary, and provides more rigorous derivations of speaker expectation biases with NPQs - their existence, specific polarity, and strength. Section 3.1 provides background on the assumed semantics for modals and notion of discourseoriented use. Section 3.2 shows how we can capture the context-managing role of VERUM utilizing the general semantic and pragmatic resources from Section 3.1. Drawing on independently motivated apparatus from literatures on modals and a general principle of discourse relevance (Section 3.3), I show how we can capture the discourse differences between NPQs and epistemic modal questions and derive the distinctive speaker expectation biases of NPQs (Section 3.4).

\subsection{Endorsing and Discourse-Oriented Use}

It's common to distinguish endorsing uses of modal expressions, in which the speaker is presented as endorsing the considerations with respect to which the modal is

\footnotetext{
${ }^{12}$ An alternative Repp-style account, which treats preposed negation as having an epistemic semantics, is briefly considered in Section 4.2 .
} 
interpreted, and non-endorsing uses, in which the speaker isn't presented in this way (cf. Lyons [35, 36]). ${ }^{13}$ The non-endorsing deontic use in (46) reports what Ed's parents' rules require. The non-endorsing epistemic use in (47) describes what is possible/necessary according to the information provided in the filing cabinet. The verifying norms/information in (46)-(47) needn't be accepted by the speaker.

(46) Ed has to be home by 10. Aren't his parents stupid? I'd stay out if I were him. a. $\approx$ According to Ed's parents' rules, Ed has to be home by 10 .

[Context: We're standing before a locked filing cabinet. None of us has had access to the information in it, but we know it contains the police's complete evidence about the murder of Klotho Fischer and narrows down the set of suspects. We're betting on who might have killed Fischer according to the information in the filing cabinet. You, who we all know is innocent, say:]

I might/must have done it.

(adapting Kratzer [30, 98-99])

By contrast, in (48)-(49) A's utterances express her acceptance of norms implying that Sally contribute to prison reform, and her acceptance of information compatible with the butler's being the killer, respectively. A prototypical function of such uses is to coordinate on what information, norms, etc. to accept in the discourse, as reflected in $B$ 's replies.

A: Sally must contribute to prison reform. She has the resources, and they need our support.

$B$ : Yeah, you're right.

$B^{\prime}$ : No, it's fine the way it is.

A: The butler might be the killer.

$B$ : Yeah, we can't rule him out. We still need to see if his alibi checks out.

$B^{\prime}$ : No, it can't be him. It must have been the gardener; I saw him lurking around before the crime.

Given the prominence of appeals to special discourse-oriented operators in accounts such as R\&Hs, it is worth spelling out how the expressive/context-managing properties of endorsing uses in assertions and questions may be captured without assuming such operators. To illustrate how the account may be developed with minimal revisionary apparatus, I assume a classical contextualist semantics which implements the context-sensitivity of the relevant epistemic expressions in same kind of way as the context-sensitivity of individual pronouns, quantifiers, etc.; I assume in particular the sort of contextualist approach developed in Silk [65, 66]. Read-

\footnotetext{
${ }^{13}$ This distinction has been noted in many areas under various labels; see also Hare [24], von Wright [91], Narrog [42], Verstraete [89], Silk [65, 66]. Expressions may differ in tendencies for endorsing/nonendorsing use; e.g., for deontic readings of modal verbs, 'must' is typically used endorsingly, whereas 'have to' is more flexible (e.g. Ernst [13], Van Linden [87], Silk [65, 69]). I use 'endorsement' as a cover term for acceptance attitudes of various kinds; one can "endorse" (accept) information, norms, goals, etc.
} 
ers favoring relativist/expressivist semantics may adapt the discussion accordingly (see n. 9).

Following common practice I treat modal operators as semantically associated with a variable determining a set of premises (propositions) (Kratzer [27, 28]). ${ }^{14}$ Since modals can occur in intensional contexts, premise sets are indexed to a world of evaluation. What context supplies for interpretation is a premise frame: a function $P$ from worlds $w$ to premise sets $P(w)$. Epistemic readings call for a premise frame that encodes a body of information. Using Sal might $\mathbf{P}_{7}$ have killed Fischer in the context in (47) assumes that context determines an assignment $g_{c}$ that maps the (typed) premise-frame pronoun $\mathbf{P}_{7}$ to a premise frame $P$ encoding the salient information provided in the filing cabinet, and asserts that $g_{c}(7)(w)$ is compatible with the proposition $k$ that Sal killed Fischer.

$\llbracket$ Sal might $\mathbf{P}_{7}$ have killed Fischer $\rrbracket^{c, g_{c}}\left(w_{0}\right)=1$ iff $\bigcap\left(g_{c}(7)\left(w_{0}\right) \cup\{k\}\right) \neq \emptyset$

Endorsing uses of epistemic modals (hereafter endorsing-epistemic uses) call for an epistemic premise frame variable that represents information endorsed in the context (Silk $[65,66]$ ). For expository purposes I use ' $\mathbf{P}_{\mathbf{e}}$ ' for the variable invoked in endorsing-epistemic uses, with the subscript ' $e$ ' to indicate the intended index/assignment and interpretation of the variable. In the unembedded case $\mathbf{P}_{\mathbf{e}}$ typically corresponds to the discourse common ground, the information taken for granted in the conversation. This reflects the paradigmatic role of epistemic modals in communal inquiry. Generally put, an endorsing-epistemic use of Must/Might $p$ assumes a value for $\mathbf{P}_{\mathbf{e}}, P_{e}$, and is true at $w$ iff $p$ follows from/is compatible with $P_{e}(w)$.

This framework provides an attractive way of characterizing the roles of epistemic language in expressing speakers' states of mind and managing the discourse common ground. ${ }^{15}$ First, note that there is no reference to the discourse context or "the relevant information," considered de dicto, in the content of an epistemically modalized sentence. Common characterizations of contextualism notwithstanding (e.g. Silk [61, 212-213], MacFarlane [37, 146-147]), on the present semantics epistemic modal sentences aren't fundamentally about an individual, group, or discourse context; they make claims about the logical properties of a given epistemic premise frame. Endorsing-epistemic uses don't simply say what is possible, necessary, etc. according to some body of information; they assume that the information is to be accepted in

\footnotetext{
${ }^{14}$ I assume that premise set parameters are syntactically realized as pronouns (cf. von Fintel and Heim [17]). The premise-semantic implementation assumed here is equivalent (Lewis [34]) to the implementation in Kratzer [28, 29] which uses a set of propositions to preorder the set of accessible worlds. Kratzer's $[28,29]$ semantics uses two premise sets: a "modal base" $F(w)$ that describes some set of background facts in $w$, and an "ordering source" $G(w)$ that represents the content of some ideal in $w$. This complication won't be relevant here; I treat modals as evaluated with respect to a single finite, consistent premise set. I sometimes suppress world-indexing on premise sets; talk about $p$ "following from (/being compatible with) $P$ " is short for saying that $p$ follows from (/is compatible with) $P(w)$, for any relevant world $w$. I address further details of the formal semantics shortly (see also Silk [65, 66]). I use bold for variables, and italics for their values in context.

${ }^{15}$ The following discussion draws on material in Silk [65, ch. 3].
} 
the discourse. ${ }^{16}$ This feature will be important when comparing the proposed account of VERUM and NPQs with the context-managing operator accounts from Section 2.

Second, it's well-known that in discourse we keep track of information not only about the subject matter of the discourse but also about the discourse situation itself. The worlds in the context set CS fix facts about the interlocutors, the extra-linguistic context, and the semantic values of expressions (cf. Stalnaker [73, 76]). So, one effect of accepting an endorsing-epistemic use of e.g. Must $p$ is that the CS is updated to include only worlds in which (among other things) the concrete discourse situation determines an abstract representation of context $g$ that maps $\mathbf{P}_{\mathbf{e}}$ to an epistemic premise frame that implies $p$, i.e. a set of worlds in which the interlocutors endorse information that implies $p$. Compare how $S$ 's utterance in (51) may update attention to a certain baby $b$, conveying $S$ 's assumptions about what individual is to be treated as maximally salient; and how accepting $S$ 's utterance updates the CS to a set of worlds in which the concrete discourse determines an abstract representation of context $g$ mapping $i$ to $b, b$ is salient, and $b$ is laughing.

a. S: Look, he ${ }_{i}$ 's laughing.

b. $\llbracket$ he $_{i}$ is laughing $\rrbracket^{c, g_{c}}\left(w_{0}\right)=1$ iff $g_{c}(i)$ is laughing in $w_{0}$

Uses of context-sensitive expressions thus reflect speakers' assumptions about the relevant content-determining features of context. Although the compositional semantics takes as given a particular abstract assignment which supplies values for (e.g.) pronouns, what contextual resolution is determined can become at-issue, or have main-point status, in concrete utterances (cf. Thomason et al. [82], Simons [70], Silk [65]). Consider (52) from Silk [62].

[Context: It's America before the ratification of the Nineteenth Amendment. Chip is a well-known sexist.]

Chip: $\quad$ Ain't America great? Everyone can vote.

Dorothy: No, not everyone can vote. I still can't.

Roughly, Chip's utterance says that every relevant individual in America can vote - slightly less roughly, that every individual in America with a moral right to vote is legally permitted to vote. Insofar as Chip intends to say something true, it's mutually obvious that he is assuming that women aren't to be considered in questions about voting rights. To avoid encouraging further discrimination in the future, Dorothy acts in a way which assumes that Chip's assumption is false; her utterance assumes that women aren't to be excluded from the conversationally relevant domain of individuals. Chip's and Dorothy's contrasting contextual assumptions can lead to negotiation about which individuals have a moral right to vote and why.

\footnotetext{
${ }^{16}$ In a relativist or expressivist implementation, the resolution of the pronoun in endorsing uses would be abstracted over in the truth-conditional content (broadly construed) or directly targeted in the semantic update, as in e.g. (i), where $\llbracket \mathbf{P}^{*} \rrbracket^{g_{c}, P^{*}}=P^{*}$ is an informational parameter added in the index of evaluation (see n. 9).
}

$$
\llbracket \text { might } \mathbf{P}^{*} \rrbracket^{g_{c}, P^{*}}(p)\left(w_{0}\right)=1 \text { iff } \bigcap\left(P^{*}\left(w_{0}\right) \cup\{p\}\right) \neq \emptyset
$$


Epistemic modal sentences semantically express propositions about logical relations between propositions and premise sets. Such logical matters aren't typically what is at-issue in conversation. What is typically interesting in a speaker's epistemic modal utterance is a certain assumption of its use: that the endorsed information, and hence value for $\mathbf{P}_{\mathbf{e}}$, is such as to make one's utterance true. It is this assumed value for $\mathbf{P}_{\mathbf{e}}$ that delineates the live possibilities in the conversation. Epistemic modals afford an efficient means of managing interlocutors' assumptions about what information to take for granted in the conversation. ${ }^{17}$

Let's return to questions. Consider (53). Intuitively, $S$ 's question targets the relevant standard $i$ associated with rich-how rich one must be to count as rich. If $A$ gives a yes-answer - roughly, that Rita's income is at least as great as $g_{c}(i)-S$ can infer that $A$ assumes $g_{c}(i)$ is no greater than $\$ X / y r$. Analogous phenomena occur with epistemic modal questions such as (54) (hereafter endorsing-epistemic questions).

[Context: $S$ knows approximately how much money Rita earns (say, $\$ X / y r$ ), and $S$ thinks $A$ does too. Hoping to ascertain $A$ 's views on whether such a salary counts as rich, $S$ asks:]

Is Rita $\operatorname{rich}_{i}$ ?

(54) [Context: $S$ isn't sure who the killer is, and wants to see if $A$ has a better idea. $S$ asks:]

Might the gardener have done it?

Intuitively, $S$ 's question targets the relevant information associated with the modal. It's not that $S$ is inquiring about the logical implications of such-and-such mutually accepted body of evidence. $S$ wants to ascertain if $A$ has evidence that rules out the possibility $d$ that the gardener is the killer. If $A$ gives a no-answer-roughly, that $\llbracket \mathbf{P}_{\mathbf{e}} \rrbracket$ is incompatible with $d-S$ can infer that $A$ isn't treating $d$ as a live possibility.

Call uses such as those in (48)-(49), (52)-(54) — uses which distinguish among worlds in the CS based on features determining the representation of context $g_{c}$ in those worlds, and propose to adjust live values for a contextual parameter-discourse-oriented uses. It's controversial how to model the discourse dynamics of discourse-oriented uses (in my terminology) in assertions and questions (for relevant discussion see Barker [4], Murray [41], Silk [63, 65, 68]; also n. 9). What is important here is simply that uses of endorsing-epistemic questions in conversation can have an effect of partitioning the worlds in the CS based on whether the concrete discourse situation in those worlds determines a value for $\mathbf{P}_{\mathbf{e}}$ that bears the stated logical relation to the proposition embedded under the modal. ${ }^{18}$ One effect of

\footnotetext{
${ }^{17}$ The relevant attitude toward the proposition that the context, hence contextually determined assignment, is thus-and-so isn't belief but acceptance for purposes of the conversation (Stalnaker [72], Thomason [81]). In endorsing-epistemic uses one needn't believe that the assumed information is commonly accepted prior to one's utterance (cf. Stalnaker [74]). See Silk [65] for extensive discussion of this feature of epistemic modals and differences among context-sensitive expressions in tendencies for (non-)discourse-oriented use. ${ }^{18}$ More precisely: ... an effect of partitioning the worlds $w$ in the CS based on whether the concrete discourse determines an abstract representation of context $g_{c_{w}}$ which supplies such a value. My talk about concrete discourses determining values for variables can be understood as short for the latter formulation in terms of contextually determined assignments.
} 
accepting a no-answer to (54) is that the CS is updated to a set of worlds in which the interlocutors endorse information that excludes the proposition $d$ - formally, in which the concrete discourse determines a value for $\mathbf{P}_{\mathbf{e}}$ that is incompatible with $d$. This is parallel to how one effect of $S$ 's utterance in (53) is that the worlds in the CS are partitioned based on whether the concrete discourse situation in those worlds determines a standard for rich, $r_{c}$, such that Rita's income is at least $r_{c}$; and one effect of a yes-answer is that the CS is updated to a set of worlds in which this is the case.

This section has examined how phenomena of context-management can arise with context-sensitive language generally. The following sections examine how the general resources from this section may be applied to VERUM and NPQs.

\subsection{Verum as a Conventionally Endorsing Epistemic Operator: Attitude Expression and Context Management with VERUM}

I suggest that we capture VERUM's expressive and context-managing roles by treating it as conventionally endorsing, in the sense of Section 3.1. A preliminary lexical entry is in (55) (see nn. 1, 14; $j$ is the set of worlds in which Jane is coming to the party). ${ }^{19}$

$\llbracket$ VERUM $\rrbracket^{c, g_{c}}=\lambda P_{\langle s,\langle s t, t\rangle\rangle} \cdot \lambda p_{s t} \cdot \lambda w_{s}: P$ is a body of information endorsed in $c \cdot \bigcap P(w) \subseteq p$ (preliminary) $\llbracket$ VERUM $\mathbf{P}_{\mathbf{e}}$ Jane is coming $\rrbracket^{c, g_{c}}\left(w_{0}\right)$ is defined only if $g_{c}(e)$ is a body of information endorsed in $c$. Where defined,

$\llbracket$ VERUM $\mathbf{P}_{\mathbf{e}}$ Jane is coming $\rrbracket^{c, g_{c}}\left(w_{0}\right)=1$ iff $\bigcap g_{c}(e)\left(w_{0}\right) \subseteq j$

This semantics predicts straightway VERUM's roles in managing the CG and in expressing speakers' attitudes, both about the subject matter of the discourse and about the discourse situation. Using VERUM $p$ conventionally conveys that the verifying information is endorsed in the context and that this information implies $p$. The speaker expresses her state of mind about $p$ - her acceptance of $p$ - in the sense of performing an act that is appropriate only if she is in that state of mind (cf. Bach and Harnish [3]). Given what the common ground CG represents - a body of information accepted for purposes of conversation - using VERUM $p$ thus expresses the speaker's intention to update the CG to a value that implies $p$. This value can be managed in subsequent discourse via the general mechanisms of discourse-oriented use described in Section 3.1.

The present account avoids the worries with conflating VERUM with epistemic attitude predicates (Section 2.2). Suppose with $R \& H$ that epistemic really has the same semantics as VERUM. Using really assumes an epistemic premise frame which represents a body of contextually endorsed information. In uttering Really $p$ the speaker expresses her attitudes about $p$ and the proper discourse status of $p$; she doesn't

\footnotetext{
${ }^{19}$ I continue to use $\mathbf{e} / e$ to indicate the intended reading (index, assignment), and use variables $p, q$, etc. both for $\langle s, t\rangle$ functions and their characteristic sets (sets of worlds). I will often suppress reference to the assignment, and omit the definedness condition that $\llbracket \mathbf{P}_{\mathbf{e}} \rrbracket$ be a body of contextually endorsed information.
} 
report them. ${ }^{20}$ So, in (57), while there may be something odd in reporting that one is certain about one's own fatigue (as if it was something one might be mistaken about), there is nothing odd in intending to ensure that one's fatigue be explicitly registered in the body of contextually endorsed information.
a. ?I am sure I am tired.
b. I really am tired.

Really $p$ isn't semantically or conversationally equivalent to I know p, I'm sure that $p$, I'm certain that we should accept $p$, etc.

Giving VERUM a semantics of epistemic necessity doesn't require identifying it as an epistemic modal verb/adverb. There are linguistic differences among VERUM and categories of epistemic modal expressions. For instance, uses of epistemic Must $p$ generally imply that $p$ is the conclusion of an inference (Karttunen [26], von Fintel and Gillies [16]); no such implication is observed with VERUM:

[Context: I directly introspect that I'm tired.]

a. I really am tired.

b. \#I must be tired.

[Context: $A$ and $B$ are talking on the phone.]

$A$ : At least it isn't raining by you.

$B$ : No, it really is raining. I'm looking out the window.

$B^{\prime}$ : \#No, it must be raining. I'm looking out the window.

Whereas epistemic must generally scopes over negation, VERUM patterns with certain epistemic adverbs in being able to scope under negation (e.g. Ernst's [13] weak PPIs (probably) and non-PPI evidentials (obviously)). In languages such as English, context must supply a type of reading for modal verbs to have a specific interpretation; even fixing a particular type of reading (e.g. epistemic), non-endorsing uses are generally possible. VERUM, in contrast, is lexically specific both for modal flavor (epistemic) and endorsing use. ${ }^{21}$

\footnotetext{
${ }^{20}$ The importance of the express/report distinction has a rich history in metaethics (e.g. Stevenson [78], Gibbard [19]); see also nn. 9, 13.

${ }^{21}$ A qualification: In Section 1 we observed that NPQs can sometimes convey a normative expectation, e.g.:

(i) a. Aren't you ashamed of yourselves?

b. Are you really not ashamed of yourselves?
}

One approach would be to treat VERUM as lexically flavor-neutral, as reflected in (ii), though perhaps receiving epistemic readings by default. On this line, using VERUM in (i) would directly express an intention to update the norms accepted for purposes of conversation (Portner [45], Silk [65, 67]) to a value that implies $p$.

(ii) $\llbracket$ VERUM $\rrbracket^{c, g_{c}}=\lambda P_{\langle s,\langle s t, t\rangle\rangle} \cdot \lambda p_{s t} \cdot \lambda w_{s}: P$ is a body of considerations (information, norms) endorsed in $c$. $P(w) \subseteq p$

An alternative is to treat VERUM as uniformly epistemic and derive the normative character of the expectation in (e.g.) (i) as an implicature. It isn't implausible that performing an act expressing that one presupposes $p$ when the truth of $p$ is under the control of the addressee may, in suitable contexts, convey a normative expectation that the addressee see to it that $p$ (cf. Bybee et al. [11], Silk [69]). For present purposes I assume the latter option and treat VERUM as lexically specific for modal flavor (epistemic), as well as strength (necessity) and endorsing use. 
To recap: I have suggested that we give VERUM the semantics of an epistemic necessity operator lexically specified for endorsing use. VERUM is conventionally interpreted with respect to a premise frame representing a body of contextually endorsed information. We can capture the intuition that uses of VERUM conventionally express speakers' attitudes about the common ground and how it should evolve, without encoding a metacontextual element in the conventional content. Contextmanagement with VERUM is explained in terms of general mechanisms associated with discourse-oriented uses of context-sensitive language. The account avoids the technical problems with R\&H's formalization, and provides independently motivated resources for capturing VERUM's expressive and context-managing roles.

\subsection{Structured Information States and Discourse Relevance}

Let's return to NPQs and speaker expectation biases. Following R\&H I assume that the preposing of negation introduces VERUM. In Section 2 we saw that R\&Hs account starts by deriving the existence of a bias from an economy principle (17). Analyzing VERUM as a conventionally endorsing epistemic operator might seem to help capture the existence of a bias without requiring a non-violable pragmatic principle specific to "meta-conversational" moves and "unbalanced" partitions: Ordinary assertions and questions are conventional devices for managing the CG and structuring inquiry; so, using an additional device like VERUM will be generally infelicitous unless one has special reasons to do so-say, unless the speaker has some views about $p$ and its proper discourse status, and strong enough views to warrant invoking a conventional endorsing device. Yet such an implicature falls quite short of a fullblown epistemic bias. As we saw in Section 2.4, one may have doubts about adding $p$ to the CG, and use VERUM, while having equal credence in $p$ and $\neg p$. This section develops an account of speaker expectation biases which doesn't require giving economy a central explanatory role. The account captures the existence of a bias as well as its specific content, polarity, and strength.

A preliminary denotation for an NPQ Isn't Jane coming too? is in (60) (nn. 1, 19). ${ }^{22}$ As per our discussion of the discourse dynamics from Section 3.1, uttering (60) has an effect of (among other things) partitioning the worlds in the CS based on whether the concrete discourse situation in those worlds determines a value for $\mathbf{P}_{\mathbf{e}}$ that implies $j$ (n. 18); and one effect of accepting (say) a yes-answer is that the $\mathrm{CS}$ is updated to a set of worlds in which the interlocutors endorse information that implies $j$.

(60) Isn't Jane coming to the party (too)?

$(\mathrm{NPQ} \sim j ?)$

a. LF: [ $Q$ not [VERUM $\mathbf{P}_{\mathbf{e}}$ [Jane is coming (too)]]]

b. $\quad \llbracket(60 \mathrm{a}) \rrbracket^{c, g_{c}}\left(w_{0}\right)=\left\{\lambda w \cdot \bigcap \llbracket \mathbf{P}_{\mathbf{e}} \rrbracket(w) \subseteq j, \lambda w \cdot \bigcap \llbracket \mathbf{P}_{\mathbf{e}} \rrbracket(w) \nsubseteq j\right\}$

\footnotetext{
${ }^{22}$ I will often leave $\llbracket \mathbf{P}_{\mathbf{e}} \rrbracket$ unspecified in question denotations because of the issues in Section 3.1 concerning local readings under the question operator.
} 
Treating VERUM as an epistemic necessity operator makes vivid the challenge for context-management accounts from Section 2.4 of distinguishing NPQs from associated epistemic modal questions. Compare the "intent" - denotation and pronounced cell — in (63) for NPQs $\sim p$ ? with the intent in (64) for endorsing uses of epistemic possibility questions (EPQs) such as (61) (nn. 1, 19). (Unless otherwise noted, assume that all uses of epistemic possibility expressions are endorsing uses, abbreviated $\nabla_{e}$, i.e. uses interpreted with respect to a premise frame variable representing a body of contextually endorsed information.)

$$
\begin{aligned}
& \text { a. Is Jane perhaps/maybe/possibly not coming? } \\
& \text { b. Might Jane not be coming? }
\end{aligned}
$$

$$
\begin{aligned}
& \llbracket \nabla_{e} p \rrbracket^{c, g_{c}}\left(w_{0}\right)=1 \text { iff } \bigcap\left(\llbracket \mathbf{P}_{\mathbf{e}} \rrbracket\left(w_{0}\right) \cup\{p\}\right) \neq \emptyset \\
& N P Q \sim p ? \text { Intent } \\
& \quad\left\{\lambda w \cdot \bigcap \llbracket \mathbf{P}_{\mathbf{e}} \rrbracket(w) \subseteq p, \lambda w \cdot \bigcap \llbracket \mathbf{P}_{\mathbf{e}} \rrbracket(w) \nsubseteq p\right\} \\
& E P Q \nabla_{e} \neg p ? \text { Intent } \\
& \quad\left\{\lambda w \cdot \bigcap\left(\llbracket \mathbf{P}_{\mathbf{e}} \rrbracket(w) \cup\{\neg p\}\right) \neq \emptyset, \lambda w \cdot \bigcap\left(\llbracket \mathbf{P}_{\mathbf{e}} \rrbracket(w) \cup\{\neg p\}\right)=\emptyset\right\}
\end{aligned}
$$

The pronounced cell of $\sim p$ ? is the set of worlds $w$ such that $\llbracket \mathbf{P}_{\mathbf{e}} \rrbracket(w)$ doesn't imply $p$; the pronounced cell of $\nabla_{e} \neg p$ ? is the set of worlds $w$ such that $\llbracket \mathbf{P}_{\mathbf{e}} \rrbracket(w)$ is compatible with $\neg p$. Given that $\llbracket \mathbf{P}_{\mathbf{e}} \rrbracket(w)$ is a set of propositions, the pronounced cells are logically equivalent. But if an NPQ $\sim p$ ? and an EPQ $\diamond \neg p$ ? have the same intent - "pursuing the topic 'lack of complete certainty about $p$ ' or 'possible... doubts about $p$ ", (Romero and Han [57, 646]) — whence their discourse differences? Why does the NPQ, unlike the EPQ, invariably convey a prior expectation that $p$ ? Why can the EPQ, unlike the NPQ, be used to raise the possibility that $\neg p$ ? Even bracketing the differences in polarity of the observed epistemic implicatures, why does an NPQ invariably express an antecedent bias about $p$, while an EPQ need only express some credence? These questions are pressing for any broadly epistemic approach to NPQs.

Our aim is to distinguish the negated necessity answer $\neg \square$ in an NPQ from the possibility answer $\diamond \neg$ in an EPQ. We need a semantics which distinguishes a state of not accepting the epistemic necessity of $p$ from a state of committing to the epistemic possibility of $\neg p$. Such a distinction is independently motivated by work on attention and attitude ascriptions with epistemic modals (Franke and de Jager [18], Rothschild [59], Yalcin [93], Willer [90]). In (65) you might fail to accept that it must be raining in Abuja because you have alternative views about the weather there; but you also might fail to accept it because you have never considered the question. Even if asked, you might have no idea what to say. In the discourse in (66), the possibility of John's being home changes from being merely compatible with what is taken for granted to being a relevant live possibility.

$S: \quad$ Might it be raining in Abuja? Do you think it's possible?

A: Abuja? Where's that? I have no idea. I don't know whether it might be raining there. 
(66) A: I can't find John. Do you know where he is?

$B$ : He might be at home.

A: Oh, OK, I'll call him and check.

(Willer [90, ex. 6])

Treating $p$ as a live possibility is more committal than merely failing to accept $\neg p$.

One way of capturing these distinctions is to enrich the structure of bodies of information and attitude states. Following moves in formal epistemology and epistemic modals literatures, I represent informational states with a set of sets of propositions (cf. Beaver [5], Rothschild [59], Yalcin [93], Willer [90], Moss [40]; see Silk [64, §4.2] on deontic modals). A revised semantics for epistemic possibility/necessity operators $\diamond / \square$ is as follows, where $\llbracket \mathcal{P} \rrbracket=\mathcal{P}$ is a set of premise frames representing a body of information. Denotations with epistemic modal verbs are in (69) ( $i$ now a typed index for type $\langle\langle s,\langle s t, t\rangle\rangle, t\rangle)$.

$$
\begin{aligned}
& \llbracket \diamond \rrbracket^{c, g_{c}}(\mathcal{P})(p)(w)=1 \text { iff } \forall P \in \mathcal{P}: \bigcap(P(w) \cup\{p\}) \neq \emptyset \\
& \llbracket \square \rrbracket^{c, g_{c}}(\mathcal{P})(p)(w)=1 \text { iff } \forall P \in \mathcal{P}: \bigcap P(w) \subseteq p \\
& \llbracket \text { It might } \mathcal{P}_{\boldsymbol{i}} \text { be raining } \rrbracket^{c, g_{c}}\left(w_{0}\right)=1 \text { iff } \forall P \in g_{c}(i): \bigcap\left(P\left(w_{0}\right) \cup\{\text { rain }\}\right) \neq \emptyset
\end{aligned}
$$

This says that $p$ is epistemically necessary/possible iff $p$ follows from/is compatible with every epistemic premise set in the given set $\mathcal{P}$. A possibility $p$ can be merely compatible with a body of information $\mathcal{P}$, and $\neg p$ can fail to be accepted as epistemically necessary, without it being the case that $p$ is delineated as a live possibility: $\neg \square \neg p$ is true iff some epistemic premise frame in $\mathcal{P}$ is compatible with $p$, but the truth of $\diamond p$ requires that every epistemic premise frame in $\mathcal{P}$ be compatible with $p$. Interlocutors can fail to presuppose $\neg p$ without thereby committing to the possibility that $p .^{23}$

Extending the general semantics for epistemic operators in (67)-(68) to VERUM and endorsing uses of epistemic modals yields distinct denotations and pronounced cells (intents) for an NPQ $\sim p$ ? and EPQ $\diamond_{e} \neg p$ ?, as reflected in (70)-(73), where $\mathcal{P}_{\mathrm{e}}$ is the variable for a set of epistemic premise frames representing a body of contextually endorsed information (nn. 1, 19). As in our preliminary semantics, VERUM is distinguished from universal modal expressions such as 'have to' in lexically specifying modal flavor (epistemic) and endorsing use (n. 21).

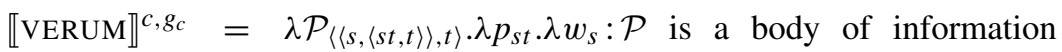
endorsed in $c . \forall P \in \mathcal{P}: \bigcap P(w) \subseteq p$

a. $\quad$ VERUM $\mathcal{P}_{\mathbf{e}} p \rrbracket^{c, g_{c}}\left(w_{0}\right)$ is defined only if $g_{c}(e)$ is a body of information endorsed in $c$. Where defined,

$\llbracket \operatorname{VERUM} \mathcal{P}_{\mathbf{e}} p \rrbracket^{c, g_{c}}\left(w_{0}\right)=1$ iff $\forall P \in g_{c}(e): \bigcap P\left(w_{0}\right) \subseteq p$

b. $\llbracket \diamond_{e} \neg p \rrbracket^{c, g_{c}}\left(w_{0}\right)=1$ iff $\forall P \in g_{c}(e): \bigcap\left(P\left(w_{0}\right) \cup\{\neg p\}\right) \neq \emptyset$

$$
\begin{aligned}
& \quad N P Q \sim p ? \text { Intent } \\
& \quad\left\{\lambda w . \forall P \in \llbracket \mathcal{P}_{\mathbf{e}} \rrbracket: \bigcap P(w) \subseteq p, \underline{\lambda w} . \neg \forall P \in \llbracket \mathcal{P}_{\mathbf{e}} \rrbracket: \bigcap P(w) \subseteq p\right\}
\end{aligned}
$$

\footnotetext{
${ }^{23}$ I treat possibilities as propositions. In saying that one "accepts the possibility of $p$ " or "treats a possibility $p$ as live," I mean that one's information state $\mathcal{P}$ verifies $\diamond p$.
} 


$$
\begin{aligned}
& E P Q \nabla_{e} \neg p ? \text { Intent } \\
& \quad \frac{\left\{\lambda w . \forall P \in \llbracket \mathcal{P}_{\mathbf{e}} \rrbracket: \bigcap(P(w) \cup\{\neg p\}) \neq \emptyset,\right.}{\left.\lambda w . \neg \forall P \in \llbracket \mathcal{P}_{\mathbf{e}} \rrbracket: \bigcap(P(w) \cup\{\neg p\}) \neq \emptyset\right\}}
\end{aligned}
$$

The pronounced cell in the EPQ asymmetrically implies the pronounced cell in the NPQ: the latter is that $\neg p$ isn't incompatible with the relevant information; the former is that $\neg p$ is a live possibility. ${ }^{24}$

How might the contrasting intents in (72)-(73) help explain the discourse differences between NPQs and associated EPQs? To address this issue I offer the relevance condition in (74), adapted from Roberts [52] and Simons et al. [71], where the Question Under Discussion (QUD) is a set of alternative propositions representing the current discourse topic.

An utterance is felicitous only if it is relevant to the Question Under Discussion (QUD), where

a. An assertion is relevant to a QUD iff accepting it contextually implies an epistemic commitment toward a partial/complete answer to the QUD.

b. A question is relevant to a QUD iff it has an answer such that accepting that answer contextually implies an epistemic commitment toward a partial/complete answer to the QUD.

Roberts and Simons et al. define relevance in terms of (contextual) implication between a discourse move's truth-conditional content and the QUD. The requirement in (74) differs in two respects. First, I characterize relevance at the level of acceptance. This captures the relevance of discourse-oriented uses (Section 3.1) discourse moves adjusting the value of a contextual parameter. Suppose the QUD is who is coming to the party, and $S$ utters Jane really is coming. The truth-conditional content of the sentence Jane really is coming is that a certain body of information implies that Jane is coming. This logical proposition needn't imply that Jane is coming. Yet $S$ 's utterance is relevant insofar as accepting it would require $(a)$ accommodating a value for $\mathcal{P}_{\mathbf{e}}$ that implies that Jane is coming and $(b)$ adjusting the $\mathrm{CG}$ accordingly given what $\mathcal{P}_{\mathbf{e}}$ represents, namely a body of contextually endorsed information. What is important for relevance is that the discourse move would land one in a context that accepts an answer to the QUD.

Second, I characterize relevance in terms of implying an epistemic commitment. The intuitive idea motivating the account of relevance is that discourse moves are relevant by being "part of a strategy" to resolve the QUD (Roberts [52, 16]; emphasis added). A discourse move can be part of a strategy to resolve a question not only by introducing an answer. Suppose that the QUD is who is coming to the party, and $S$ utters Maybe Jane is coming. Accepting $S$ 's assertion needn't imply accepting a partial answer to the QUD, though it might raise the likelihood of accepting such an answer, e.g. by directing the conversation toward examining possible evidence for $j$.

\footnotetext{
${ }^{24}$ I will say that a body of information $\mathcal{P}$ implies $p$ iff every premise frame in $\mathcal{P}$ implies $p$, i.e. $\forall P \in \mathcal{P}: \bigcap P(w) \subseteq p$; and that $\mathcal{P}$ is compatible with $p$ iff $\exists P \in \mathcal{P}: \bigcap(P(w) \cup\{p\}) \neq \emptyset$.
} 
Yet even this arguably isn't necessary for relevance. Suppose the QUD is whether there are spiritual beings, and Agnostic utters Maybe God exists, and maybe God doesn't exist; we'll never know. Accepting Agnostic's assertion needn't raise the likelihood of accepting an answer to the QUD: Agnostic accepts both the non-eliminable epistemic possibility that God exists and the non-eliminable epistemic possibility that God doesn't exist. However, accepting her assertion does commit one to a stable epistemic attitude toward an answer to the QUD — settled agnosticism toward the proposition that God exists. $S$ 's and Agnostic's assertions are part of a strategy to resolve the QUD, hence relevant.

We can represent a body of information $\mathcal{P}$ as implying an epistemic commitment E about $p$ if every "representative" in $\mathcal{P}$ agrees in delivering an E-relevant verdict about $p-$ e.g., $\mathcal{P}$ accepts $p$ insofar as every $P \in \mathcal{P}$ implies $p, \mathcal{P}$ treats $p$ as a live possibility insofar as every $P \in \mathcal{P}$ is compatible with $p$, etc. To a first approximation:

A body of information $\mathcal{P}$ implies an epistemic commitment $\mathrm{E}$ toward a proposition $p$ iff there is some E-associated relation $R$ such that for every $P \in \mathcal{P}, P$ bears $R$ to $p$.

The formulation in (75) would need to be revised to handle more refined probabilistic attitudes. The notion of relevance might also be better characterized in terms of a comparative notion of epistemic commitment. (74) could be revised to require that accepting the discourse move transitions the context to a state of stabler epistemic commitment - e.g., a narrower range of probabilities - toward an answer to the QUD. Representations of epistemic states via sets of premise sets, probability measures, etc. have been investigated extensively in formal epistemology. The characterizations in (74)-(75) should suffice for our purposes.

Finally, I assume that assertions constitute proposals to update the $\mathrm{CG}$, and that such proposals must be grounded for the update to go through (Stalnaker [73, 75], Clark and Schaefer [12], Traum [84], Gunlogson [21], Farkas and Bruce [14]). The current QUD remains active until grounding (e.g. acceptance) is signaled. I assume that if one is in a position to ground an assertion, one should.

\subsection{Deriving Speaker Expectation Biases with NPQs and EPQs}

This section applies the semantics for epistemic operators and the pragmatic principle of discourse relevance from Section 3.3 to expectation biases with NPQs $\sim q$ ? and endorsing uses of EPQs $\nabla_{e} q$ ?. I focus on the contrasting felicity patterns and attitudes conveyed in R\&H's four types of "contradiction" and "suggestion" scenarios: responding to an implication that $p / \neg p$, and suggesting $p / \neg p$ as an answer to a relevant question.

Let's start with EPQs. Accepting the pronounced cell of an EPQ $\diamond_{e} \neg p$ ? commits one to treating $\neg p$ as a live possibility (cf. (77)). The intent of the question isn't just to pursue possible doubts about $p$; it's to pursue positive reasons for treating $\neg p$ as live in the discourse. This correctly predicts, first, that $\nabla_{e} \neg p$ ? cannot be used to contradict a previous discourse move implying $\neg p$ by conveying credence in $p$, as 
in (41) reproduced in (76) (nn. 19, 22). (For readability I will use only the maybe versions in what follows.)

A: The butler is surely the killer.

$S$ : \#Was it maybe not the gardener?

$$
\begin{array}{r}
(\Rightarrow \neg g) \\
\left(\# \diamond_{e} \neg g ?\right)
\end{array}
$$

$$
\begin{aligned}
& \diamond_{e} \neg g ? \text { Intent } \\
& \quad \frac{\left\{\lambda w . \forall P \in \llbracket \mathcal{P}_{\mathbf{e}} \rrbracket: \bigcap(P(w) \cup\{\neg g\}) \neq \emptyset,\right.}{\left.\lambda w . \neg \forall P \in \llbracket \mathcal{P}_{\mathbf{e}} \rrbracket: \bigcap(P(w) \cup\{\neg g\}) \neq \emptyset\right\}}
\end{aligned}
$$

The QUD is who the killer is. Updating with the backgrounded cell of $S$ 's EPQ $\nabla_{e} \neg g$ ? wouldn't be relevant. The interlocutors already fail to mutually accept the possibility that $\neg g$. So, $S$ 's question is relevant only insofar as updating with the pronounced cell would be relevant. Updating with the pronounced cell requires treating $\neg g$ as live. Such a commitment would be implied by accepting $A$ 's assertion. So, $S$ 's question is potentially relevant only insofar as $S$ isn't implicitly grounding $A$ 's assertion and resolving the QUD. Since $S$ didn't ground $A$ 's assertion, $S$ must not be in a position to do so. So, $S$ 's utterance is potentially felicitous only insofar as $S$ wishes to raise doubts about $A$ 's implication that $\neg g$. But asking to pursue evidence for the possibility that $\neg g$ is ineffective as a means of resolving the QUD in response to an implication that $\neg g$ : if $S$ has credence in $g$ and wants to investigate this possibility, $S$ ought to direct the inquiry accordingly (cf. (78)); and if $S$ wants $A$ to confirm $A$ 's implication that $\neg g, S$ should use a stronger question that invites $A$ to do so (cf. (79)).

$$
\begin{aligned}
& S^{\prime}: \quad \text { Was it maybe the gardener instead? } \\
& \quad \text { Pronounced cell: } \lambda w \cdot \forall P \in \llbracket \mathcal{P}_{\mathbf{e}} \rrbracket: \bigcap(P(w) \cup\{g\}) \neq \emptyset
\end{aligned}
$$

$S^{\prime \prime}$ : Was it (really) not the gardener?

- Pronounced cell: $\neg g \quad\left(\lambda w . \forall P \in \llbracket \mathcal{P}_{\mathbf{e}} \rrbracket: \bigcap P(w) \subseteq \neg g\right)$

$S$ 's question is thus inappropriate as a means of advancing the discourse. An EPQ $\vee_{e} \neg p$ ? is generally infelicitous in response to a discourse move implying $\neg p$, and cannot be used to contradict an implication that $\neg p$ by conveying credence in $p$.

Likewise, an EPQ $\vee_{e} \neg p$ ? cannot be felicitously used to suggest $p$ as an answer to a relevant question (cf. (42)):

(80) [Context: Dialog between two editors of a journal in 1900:]

A: I'd like to send this paper out to a senior reviewer, but I'd prefer somebody who has experience with our regulations.

$S$ : \#Has Frege maybe not reviewed for us? He'd be a good one.

(\# $\vee_{e} \neg f$ ?, to suggest $f$ )

The implicit QUD is which senior reviewers have already reviewed for the journal; $A$ 's goal is to find such a reviewer. Updating with the backgrounded cell of $S$ 's EPQ $\nabla_{e} \neg f$ ? wouldn't be relevant. The interlocutors already fail to mutually accept the possibility that $\neg f$. Updating with the pronounced cell could be relevant, but not as a way of suggesting $f$. Delineating the possibility that $\neg f$ might advance the discourse, but only insofar as doing so might narrow the list of potential reviewers or suggest 
some other potential reviewer. (Imagine that Frege and Twin-Frege review complement sets of journals, and we can't directly access Twin-Frege's reviewing history.) So, if $S$ 's question is felicitous, it's felicitous only insofar as it excludes Frege.

Conversely, we correctly predict that an EPQ $\vee_{e} \neg p$ ? can be felicitously used in response to a discourse move implying $p$ (cf. (39)):

Moore: My hands hurt.

Skeptic: How do we know you have hands? Maybe you don't have hands and you're just a brain in a vat?

$\left(\checkmark \diamond_{e} \neg h\right.$ ?)

Moore's assertion implies $h$ that he has hands. Instead of grounding Moore's assertion, Skeptic raises the EPQ $\nabla_{e} \neg h$ ?. This question is directly relevant to the QUD of whether Moore has hands which hurt: updating with the pronounced cell implies an epistemic commitment toward the answer $\neg h$, namely committing to treating $\neg h$ as a live possibility. Skeptic's request to examine reasons for leaving open the possibility that $\neg h$ may even lead to a stable epistemic attitude about whether $h$ (e.g. acceptance that $\neg h$ or a settled credence in $\neg h$ ). Skeptic's EPQ can thus be part of a strategy for resolving the QUD, hence relevant.

$\diamond_{e} \neg p$ ? can also be felicitously used to suggest $\neg p$ (cf. Romero and Han [57, ex. 28]):

[Context: Dialog between two editors of a journal in 1900:]

A: I'd like to send this paper to a senior reviewer, but I'd prefer somebody new.

$S: \quad$ Has Frege maybe not reviewed for us? He'd be a good one.

$\left(\checkmark \diamond_{e} \neg f\right.$ ?, to suggest $\left.f\right)$

$S$ 's question is directly relevant to the QUD of which senior reviewers haven't reviewed for the journal: updating with the pronounced cell implies a commitment to treating the answer $\neg f$ as a live possibility. Pursuing reasons for leaving open the possibility that $\neg f$ may increase the likelihood of accepting at least a partial answer to the QUD and satisfying $A$ 's goal of finding a suitable reviewer.

The above account correctly predicts that EPQs $\diamond_{e} \neg p$ ? don't express a bias toward $p$. Insofar as any epistemic attitude is conveyed, it is a credence in the negative answer $\neg p$. Moreover, this credence needn't be a bias toward $\neg p$. The bias, if any, is toward the possibility that $\neg p-$ hence why Skeptic's question $\nabla_{e} \neg h$ ? need only express some credence in the skeptical scenario where you're a handless brain-in-a-vat.

Let's turn now to the felicity conditions and expectation biases with NPQs in R\&H's four types of discourse scenarios. Consider the "contradiction scenario" where the speaker utters $\sim j$ ? in response to a discourse move implying $\neg j$ (cf. (8)):

$$
\begin{aligned}
& \text { A: Andre just got here, so it looks like we're all ready to go. } \\
& (\Rightarrow \neg j) \\
& S: \text { Isn't Jane coming too? } \\
& (\checkmark \sim j ?)
\end{aligned}
$$

$$
\begin{aligned}
& \sim p ? \text { Intent } \\
& \quad\left\{\lambda w . \forall P \in \llbracket \mathcal{P}_{\mathbf{e}} \rrbracket: \bigcap P(w) \subseteq j, \underline{\left.\lambda w . \neg \forall P \in \llbracket \mathcal{P}_{\mathbf{e}} \rrbracket: \bigcap P(w) \subseteq j\right\}}\right.
\end{aligned}
$$


The speaker's expectation bias toward the positive answer $j$ can be derived as follows. A's assertion contextually implies $\neg j$. $S$ responds by asking a question with the "intent" in (84): roughly put, $S$ raises the question whether to accept information implying $j$ (more simply: whether to accept $j$ ), and pronounces the answer corresponding to not accepting $j$. Updating with the pronounced cell wouldn't be relevant. The interlocutors already fail to mutually accept $j$. (If $S$ were implicitly grounding $A$ 's assertion, the interlocutors would be in the even stronger state of accepting $\neg j$, and the QUD would be resolved.) So, updating with the pronounced cell wouldn't advance the discourse. Updating with the backgrounded cell, by contrast, would be relevant: it implies an epistemic commitment to the partial answer $j$, namely acceptance. So, $S$ 's question is potentially felicitous only insofar as $S$ wishes to pursue reasons for accepting $j$. Requesting to do so would be infelicitous if $S$ was antecedently biased toward $\neg j$, in which case $S$ could have grounded $A$ 's assertion and accepted $\neg j$. And it would be infelicitous if $S$ merely had some credence in $j$ and wanted to investigate this possibility or confirm $A$ 's implication that $\neg j$, in which case $S$ could have used a question that highlights one of these options directly, as in (85)-(86).

$$
\begin{aligned}
& S^{\prime}: \text { Is Jane maybe coming too? } \\
& \quad \text { - Pronounced cell: } \lambda w . \forall P \in \llbracket \mathcal{P}_{\mathbf{e}} \rrbracket: \bigcap(P(w) \cup\{j\}) \neq \varnothing
\end{aligned}
$$

\section{$S^{\prime \prime}$ : Is Jane not coming?}

\section{- $\quad$ Pronounced cell: $\neg j$}

Yet $S$ 's requesting to consider accepting $j$ would be felicitous if $S$ had a prior expectation that $j$. So, assuming $S$ is cooperative, $S$ must have an antecedent bias toward $j$.

Next, consider the "suggestion scenario" where the speaker utters $\sim f$ ? to suggest $f$ as an answer to a relevant question (cf. (42)).

[Context: Dialog between two editors of a journal in 1900:]

A: I'd like to send this paper out to a senior reviewer, but I'd prefer somebody who has experience with our regulations.

$S$ : Hasn't Frege already reviewed for us? He'd be a good one.

$$
(\sim f ?, \text { to suggest } f)
$$

The implicit QUD is who is an experienced senior reviewer for the journal. Updating with the pronounced cell of $S$ 's NPQ $\sim f$ ? wouldn't be relevant. The interlocutors already fail to mutually accept $f$. Updating with the backgrounded cell, by contrast, would be relevant, as it would involve accepting an answer to the QUD. So, $S$ 's question is potentially felicitous only insofar as $S$ wishes to consider accepting $f$. Requesting to do so would be infelicitous if $S$ was antecedently biased toward $\neg f$, in which case $S$ would regard them as decreasing the likelihood of correctly resolving the QUD and satisfying $A$ 's goal. And it would be infelicitous if $S$ merely had some 
credence in $f$ and wanted to investigate this possibility, in which case $S$ could have used a question that highlights this option directly:

$$
\begin{aligned}
& S^{\prime}: \text { Has Frege already reviewed for us? } \\
& \quad \text { Pronounced cell: } f \\
& S^{\prime \prime}: \text { Has Frege maybe already reviewed for us? } \\
& \quad \text { Pronounced cell: } \lambda w . \forall P \in \llbracket \mathcal{P}_{\mathbf{e}} \rrbracket: \bigcap(P(w) \cup\{f\}) \neq \emptyset
\end{aligned}
$$

However, $S$ 's requesting to consider accepting $f$ would be felicitous if $S$ had a prior expectation that $f$, in which case $S$ could provide evidence for $f$ in case $A$ lacks such evidence herself. So, assuming $S$ is cooperative, $S$ must have an antecedent bias toward $f$, and must be suggesting $f$ as an answer to the QUD.

The crucial feature of NPQs $\sim p$ ?, on the present account, is that they background the answer in virtue of which they are relevant to the discourse, the answer of accepting $p$ (more precisely, the answer of endorsing information that implies $p$ ). This feature elucidates a crucial discourse role for NPQs. Consider the contradiction scenario in (83). In uttering $\sim j$ ? $S$ chooses to background the answer - the only answer that would be relevant in the discourse - which is contrary to $A$ 's assertion, and which $S$ antecedently expected was correct. Using the NPQ provides a way of inviting $A$ to consider the alternative option of accepting $j$, yet without highlighting this alternative or contradicting $A$ directly. Correspondingly, the answer corresponding to the pronounced cell represents a weak initial way of registering disagreement with $S$ 's prior expectation; such a counter-response may subsequently be clarified with reasons supporting $A$ 's stronger implication that $\neg j$. Likewise, in (87), using the NPQ affords a relatively circumspect means of suggesting an answer to the question at hand. In backgrounding the answer of accepting $f$ - the only answer which would be relevant in the discourse $-S$ expresses her prior bias toward $f$ and suggests accepting $f$, but without explicitly asserting $f$ or directly requesting $A$ to provide confirming evidence for $f$, evidence which $A$ appears to lack herself. In using an NPQ the speaker $S$ can $(a)$ express disagreement and invite the addressee to defend a prior assertion, though without directly challenging her; and $(b)$ suggest a relevant possibility toward which $S$ is biased, though without directly asserting it. NPQs afford a means of raising the option of accepting a proposition and conveying an antecedent bias, though in a relatively modest way.

Finally, let's turn to scenarios in which $\sim p$ ? is infelicitous. An NPQ $\sim p$ ? cannot be used to contradict a prior discourse move implying $p$ by conveying credence in $\neg p$ :

$$
\begin{aligned}
& \text { A: Andre isn't coming to the party, but the rest of our cohort is. } \begin{array}{l}
(\Rightarrow j) \\
\text { S: \#Isn't Jane coming too? }
\end{array} \quad(\# \sim j ?)
\end{aligned}
$$

Updating with the pronounced cell wouldn't be relevant or advance the discourse. The interlocutors already fail to mutually accept $j$. Updating with the backgrounded cell could be relevant, but only insofar as A's assertion hasn't been grounded and the QUD remains unresolved. So, $S$ 's utterance is anomalous regardless of $S$ 's prior views about $j$ : if $S$ is biased toward $j$, she should ground $A$ 's assertion straightway; and if $S$ has doubts about $j$ and wishes to challenge $A$ 's assertion, request 
evidence supporting $A$ 's assertion, or raise the possibility that $\neg j$, she should perform a relevant discourse move that directs the inquiry accordingly, as in (90).

$S^{\prime}$ : No, Jane isn't coming either.

$S^{\prime \prime}$ : Is Jane (really) coming too?

$S^{\prime \prime \prime}$ : Is Jane maybe not coming either?

Likewise, an NPQ $\sim p$ ? cannot be felicitously used to suggest $\neg p$ as an answer to a relevant question:

(91) [Context: Dialog between two editors of a journal in 1900:]

A: I'd like to send this paper to a senior reviewer, but I'd prefer somebody new.

S: \#Hasn't Frege reviewed for us? He'd be a good one.

(\# f?, to suggest $\neg f$ )

The implicit QUD is who is a senior reviewer that hasn't reviewed for the journal. Updating with the pronounced cell of $S$ 's NPQ wouldn't be relevant. The interlocutors already fail to mutually accept $f$. Updating with the backgrounded cell could be relevant, but only insofar as it excludes Frege from consideration. If $S$ wishes to suggest $\neg f$, an additional negative element must be added, the possibility that $\neg f$ must be highlighted, or an ordinary polar question must be used:

(92) $\quad S^{\prime}$ : Hasn't Frege not reviewed for us?

$S^{\prime \prime}$ : Has Frege maybe not reviewed for us?

$S^{\prime \prime \prime}$ : Has Frege (not) reviewed for us?

There is a sense in which EPQs behave like simple positive polar questions visà-vis speaker expectation biases: an EPQ $\vee_{e} q$ ? raises the possibility that $q$ and may express a bias toward the pronounced cell, i.e. that $q$ be a live possibility. So, insofar as reasons for leaving open the possibility of $\neg p$ are reasons against $p$, an EPQ $\vee_{e} \neg p$ ? cannot be felicitously used to disagree with an implication that $\neg p$, or to suggest $p$ as an answer to a relevant question. The bias (if any) toward the possibility that $\neg p$ needn't constitute a bias toward $\neg p$. The crucial feature of NPQs is that they are relevant in virtue of their unpronounced cell - the backgrounded answer that the contextually endorsed information implies $p$ (roughly, that $p$ is accepted in the discourse). The discourse differences between NPQs and EPQs - their contrasting biases and patterns of felicitous use - are derived from these interpretive differences, further features of context, and general principles of conversation.

In closing, note that the account avoids the problems with really (not) questions from Sections 2.4-2.5. Pace R\&H (e.g. [57, 641, 650-652]), Really p? can convey merely some credence in $\neg p$ rather than a full-blown bias toward $\neg p$. Reluctant AntiSkeptic in (93) expects the positive answer $h$ that one has hands to be correct, but still has some credence in the hypothesis that one is a handless brain-in-a-vat; Settled Agnostic in (94) is unbiased, thinking both answers equally likely ( $d$ the proposition that God exists). 
(93) [Context: Reluctant Anti-Skeptic, in response to Moore's implication that $h$ :] Do you really have hands? It's hard to deny that you do, but can we rule out the possibility that you're just a brain-in-a-vat?

( $\checkmark$ Really $h$ ?, to disagree with an implication that $h$ and convey some credence in $\neg h$ )

(94) [Context: Settled Agnostic, in response to Atheist's implication that $\neg d$ :]

Does God really not exist? The arguments on both sides strike me as equally compelling. It seems just as likely that God does exist as that God doesn't.

( $\checkmark$ Really $\neg d$ ?, to disagree with an implication that $\neg d$ and convey some credence in $d$ )

Assume with R\&H that epistemic really also realizes VERUM. The predicted intent of the really not question in (94) is as follows:

$$
\begin{aligned}
& \text { Really } \neg d ? \text { Intent } \\
& \quad\left\{\lambda w . \forall P \in \llbracket \mathcal{P}_{\mathbf{e}} \rrbracket: \bigcap P(w) \subseteq \neg d, \lambda w . \neg \forall P \in \llbracket \mathcal{P}_{\mathbf{e}} \rrbracket: \bigcap P(w) \subseteq \neg d\right\}
\end{aligned}
$$

The QUD is whether God exists. Agnostic raises the question Really $\neg d$ ?, of whether to accept information that implies $\neg d$. Updating with the backgrounded cell wouldn't be relevant. The interlocutors already fail to mutually accept $\neg d$. (If Agnostic were implicitly grounding Atheist's assertion, and $\neg d$ was accepted, the QUD would already be resolved.) Updating with the pronounced cell would be relevant: it implies an epistemic commitment to the answer $\neg d$, namely acceptance. So, Agnostic's question is felicitous, but only insofar as Agnostic isn't implicitly grounding Atheist's assertion. So, Agnostic must not be in a position to do so; she must have at least some doubts about $\neg d$, and some credence in $d$. The stronger inference that Agnostic is biased toward $d$ needn't follow. The account avoids conflating NPQs $\sim p$ ? with really not questions, as in Repp's [51] and Romero's [56] FALSUM-based accounts and R\&H's [57] VERUM-based account of “inner-negation” readings (Section 1).

\section{Conclusion and Outlook}

This paper has examined distinctive discourse properties of preposed negative yes/no questions (NPQs), focusing on speaker expectation biases. Unlike positive and nonpreposed negative polar questions, using an NPQ $\sim p$ ? invariably conveys that the speaker was biased toward a particular answer, where the polarity of the bias is opposite of the polarity of the question; using the negative question $\sim p$ ? invariably expresses a prior expectation that the positive answer $p$ is correct. A prominent approach - what I called the context-management approach, developed most extensively by Romero and Han [57] — attempts to capture NPQs' expectation biases by treating NPQs fundamentally as epistemic questions about the proper discourse status of a proposition. Principal challenges are to provide more adequate formalizations of the posited context-managing content and its role in generating the observed biases, and to do so in a way that respects relevant linguistic and discourse differences with other broadly epistemic, expressive, and context-oriented devices. 
Context-management accounts highlight key features of the interpretation and discourse function of NPQs. I have argued that we can capture insights motivating context-management accounts without positing special context-managing operators or treating NPQs as questions directly about the context. For concreteness I followed Romero and Han [57] in treating the preposing of negation as introducing an additional operator. I suggested that we treat this operator as having an ordinary semantics of epistemic necessity, though lexically associated with a general kind of endorsing use observed with modal expressions. NPQs afford conventional devices for expressing speakers' attitudes and managing the discourse common ground by being interpreted with respect to an operator conventionally associated with a body of information endorsed for purposes of conversation. The distinctive biases and discourse properties of NPQs - including contrasts between NPQs and associated epistemic modal questions - can be derived from independently motivated apparatus from literatures on epistemic modals and theories of discourse: first, a distinction between possibilities that are merely compatible with a body of information and possibilities that are explicitly treated as live; second, a principle of discourse relevance, generalized to capture the relevance of epistemically hedged discourse moves and discourse moves involving discourse-oriented uses of context-sensitive language. The proposed epistemic operator account captures the expressive/context-managing roles of NPQs via general features of the meaning and use of context-sensitive language, and principles of interpretation and conversation.

In closing I would like to briefly consider several limitations of the present discussion and possible avenues for development (cf. Section 1).

\subsection{NPQs and "Denegations of Assertions"}

Context-management accounts distinguish NPQs from other types of polar questions in terms of distinctive features of an expressive/context-oriented operator. One alternative, developed by Krifka [31,32], is to explain the discourse properties of NPQs in terms of a distinctive type of speech-act. Using an NPQ $\sim p$ ?, on Krifka's view, is analyzed as asking the addressee to refrain from asserting $p$. The analysis is formalized via an additional question operator, REQUEST, which presents only one possible answer (unlike the ordinary question operator, which presents each possible answer equally) and a meta-speech-act of denegation, or failing to perform a certain speechact (cf. I don't promise to come, expressing refraining from promising to come). Krifka asserts that in using an NPQ $\sim p$ ?, "the overall intention of the speaker is to ask for confirmation for the proposition $[p]$ " $[31,31]$. No derivation of this intention is provided. One might wonder why asking the addressee to exclude asserting $p$ would invariably express a "sole interest" $[31,33]$ in $p$ or expectation that $p$. There may be independent reasons for introducing Krifka's additional question operators, speechacts, and syntactic projections for commitment and speech-act phrases; yet if the account in this paper is on the right track, such apparatus isn't necessary to capture the distinctive discourse properties of NPQs. It would be interesting to examine how 
(endorsing uses of) epistemic modal questions might be analyzed and distinguished from NPQs in a speech-act framework. ${ }^{25}$

\subsection{Preposed Negation and Epistemic Operators}

For dialectical purposes I followed $\mathrm{R} \& \mathrm{H}$ in treating the preposing of negation as introducing an additional operator, which interacts with negation. It isn't unprecedented to think that certain syntactic configurations/operations can semantically contribute an attitudinal element (e.g. McCready [39] on man) or epistemic operator (e.g. Truckenbrodt [86] on V-to-C movement in German; cf. Gutzmann [23]). ${ }^{26}$ Nevertheless one might wonder why this particular non-canonical syntax (preposing negation) would systematically trigger adding this particular operator (VERUM), given the robust crosslinguistic association between preposing negative elements and the observed discourse-oriented effects.

An alternative analysis, proposed by Repp [49-51] and taken up by Romero [56], treats preposed negation itself as a context-managing operator (Section 2.5). On the approach in this paper, preposed negation could be treated as a kind of modal negation NOT $_{\text {mod }}$ (cf. Stone and Hardt [79], Brasoveanu [8], Bittner [6], Anderbois et al. [1]), as in (96); like VERUM, NOT mod is conventionally specified for endorsing use (") for the complement of the characteristic set).

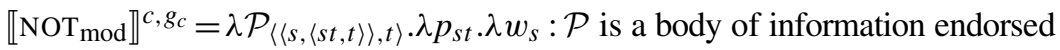
in $c . \forall P \in \mathcal{P}: \bigcap P(w) \subseteq p^{\prime}$

NPQs, on this line, would be unified with really not questions:

$$
\begin{aligned}
& \text { Isn't Jane coming? } \\
& \text { [ } Q \mathrm{NOT}_{\text {mod }} \text { [Jane is coming]] }
\end{aligned}
$$

In both (97) and (98) the relevant epistemic operator is contributed by a specific lexical item (cf. Romero and Han [57, 639n.17]). Yet the above question for the VERUM-based account arises in a new form - why preposed negation should be associated with a distinct modal lexical entry crosslinguistically. More general crosslinguistic investigation of links between non-canonical syntax and distinctive discourse effects is needed. It also remains to be seen how the derivation of speaker

\footnotetext{
${ }^{25}$ Similar points apply to the theories in Asher and Reese [2] and Reese [48] which treat NPQs as complex speech-acts - speech-acts asserting $p$ and then questioning the assertion. The account in this paper doesn't require positing a distinct conventionalized complex speech-act type, ASSERTION • QUESTION.

${ }^{26} \mathrm{R} \& \mathrm{H}$ observe that, even in English, the discourse-oriented properties and "conversational emphasis" $[57,655]$ of NPQs arise in declaratives with preposed negative elements as well:
}

(i) a. Never would Mary reveal the secret.

b. Mary would never reveal the secret.

(Romero and Han [57, ex. 122]) 
expectation biases with NPQs from Section 3.4 would carry over, and how the differences between NPQs and really not questions would be explained. The challenges for Repp's/Romero's FALSUM-based account remain pressing (Sections 2.5, 3.4).

\subsection{Answer Patterns}

There is one final puzzle with NPQs that I would like to consider, regarding answer patterns (Section 2.3). The most natural interpretation of a bare yes-answer to $\sim p$ ? is as an assertion of $p$, and the most natural interpretation of a bare no-answer is as an assertion of $\neg p$ :

(100) Isn't Jane coming?
a. Yes. (=she is)
b. No. (=she isn't)

Even if the yes-answer in (100) could be construed as meaning VERUM $j$, two questions arise: first, why the yes-answer targets the backgrounded cell; second, why the $n o$-answer seems to imply $\neg j$ rather than the weaker proposition constituting the pronounced cell (roughly, that the endorsed information fails to imply $j$ ).

First, observe that hedged answers are possible:

(101) Isn't Jane coming too?

a. Yeah, I'm not sure / I don't know. Maybe (not).

b. No, I'm not sure / I don't know. Maybe (not).

Such answers pose prima facie challenges for existing accounts. The hedged yesanswer in (101a) is surprising on R\&H's [57] account, which treats yes-answers as asserting VERUM $p$. Both (101a-b) are surprising on Romero's [54-56] account, which treats yes- and no-answers as necessarily targeting the embedded proposition p. Repp [51, 241] appeals to hedged yes-answers as evidence for her FALSUM-based account (targeted cell $\approx$ "there is some evidence for $p$ "); hedged no-answers remain unexplained. Krifka [31] treats unqualified answers as assertions of $p / \neg p$ by default. Though Krifka [31, 31] mentions the possibility of hedged yes-answers, no account is provided. It is unclear how hedged no-answers would be captured.

Suppose we follow Krifka [31] in treating answer particles as referring to a salient propositional discourse referent $(\mathrm{dr})$ and asserting it or its negation. The VERUMbased semantics from Section 3 predicts three propositional dr's with NPQs, yielding roughly the following possible distinct answers (for simplicity, ignore any differences between the assertion of $\phi$ vs. $\psi$ ):

[ $Q$ not [VERUM $[p]]]$
a. $\operatorname{dr} \phi=p$
b. $\quad \operatorname{dr} \psi=\operatorname{VERUM} p$
c. $\quad \operatorname{dr} \chi=\neg \operatorname{VERUM} p$

(103)
a. No-answer asserting $\neg \phi$
b. Yes-answer asserting $\phi(\approx \psi=\neg \chi)$
c. No-answer asserting $\neg \psi$
d. Yes-answer asserting $\chi(=\neg \psi)$ 
This answer pattern for NPQs is essentially the pattern observed in (100)-(101).

The account from Section 3 might seem to be looking pretty good in capturing answer patterns with NPQs: It captures how an unqualified yes-answer can be interpreted as asserting $p$ and cannot be interpreted as asserting $\neg p$, and how an unqualified $n o$-answer can be interpreted as asserting $\neg p$ and cannot be interpreted as asserting $p$. It makes sense of why unqualified yes-answers seem to be targeting the backgrounded cell, as they are in fact targeting the related simple propositional $\mathrm{dr} \phi$. And it predicts the possibility of hedged yes-/no-answers, and their approximate equivalence. Further, it is perhaps not surprising that simple yes-/no-answers typically target the embedded proposition, and that hedged answers are relatively less common. The QUD in uses of VERUM is typically about whether $p$ rather than about the logical properties of a certain (mutually endorsed) body of evidence. If the addressee has settled views about $p$ (e.g. in a "contradiction scenario"), she can answer an NPQ by resolving the QUD. If the addressee is unsure about $p$ (e.g. in a "suggestion scenario" or a contradiction scenario where the speaker's question leads her to rethink her previous implication), she can resort to a hedged answer that targets one of the cells in the question's denotation. That said, we should be cautious in assigning theoretical significance to hedged answers such as those in (101). Hedged answers are possible with ordinary positive polar questions and non-preposed negative questions as well.

(104) Is Jane coming?
a. Yeah, I think she is, but I'm not sure.
b. No, I think she isn't, but I'm not sure.
c. Yeah, I don't know. Maybe (not).
d. ??No, I don't know. Maybe.

(105) Is Jane not coming?
a. Yeah, I think she is (/isn't), but I'm not sure.
b. No, I think she is (/isn't), but I'm not sure.
c. Yeah, I don't know. Maybe.
d. No, I don't know. Maybe.

The matter calls for further investigation. ${ }^{27}$

Acknowledgements Thanks to an anonymous referee for comments. This research has benefited from the support of an AHRC Early Career Research Grant (AH/N001877/1) and Leverhulme Research Fellowship (RF-2018-301\0).

Open Access This article is distributed under the terms of the Creative Commons Attribution 4.0 International License (http://creativecommons.org/licenses/by/4.0/), which permits unrestricted use, distribution, and reproduction in any medium, provided you give appropriate credit to the original author(s) and the source, provide a link to the Creative Commons license, and indicate if changes were made.

\footnotetext{
${ }^{27}$ See Farkas and Bruce [14] and Roelofsen and Farkas [53] for general discussion of polarity particles and answer patterns with polar questions.
} 


\section{References}

1. AnderBois, S., Brasoveanu, A., Henderson, R. (2015). At-issue proposals and appositive impositions in discourse. Journal of Semantics, 32, 93-138.

2. Asher, N., \& Reese, B. (2007). Intonation and discourse: Biased questions. Interdisciplinary Studies on Information Structure, 8, 1-38.

3. Bach, K., \& Harnish, R. (1979). Linguistic communication and speech acts. Cambridge: MIT Press.

4. Barker, C. (2002). The dynamics of vagueness. Linguistics and Philosophy, 25, 1-36.

5. Beaver, D. (2001). Presupposition and assertion in dynamic semantics. CSLI Publications: Stanford.

6. Bittner, M. (2011). Time and modality without tenses or modals. In Rathert, M., \& Musan, R. (Eds.) Tense across languages (pp. 147-188). Niemeyer: Tübingen.

7. Bolinger, D. (1978). Yes-no questions are not alternative questions. In Hiz, H. (Ed.) Questions (pp. 87105). Dordrecht: Reidel.

8. Brasoveanu, A. (2010). Decomposing modal quantification. Journal of Semantics, 27, 437-527.

9. Brown, J., \& Cappelen, H. (Eds.) (2011). Assertion: New philosophical essays. Oxford: Oxford University Press.

10. Büring, D., \& Gunlogson, C. (2000). Aren't positive and negative polar questions the same? MS, UCLA \& UCSC.

11. Bybee, J., Perkins, R., Pagliuca, W. (1994). The evolution of grammar: Tense, aspect and modality in the languages of the world. Chicago: University of Chicago Press.

12. Clark, H.H., \& Schaefer, E.F. (1989). Contributing to discourse. Cognitive Science, 13, 259-294.

13. Ernst, T. (2009). Speaker-oriented adverbs. Natural Language and Linguistic Theory, 27, 497-544.

14. Farkas, D.F., \& Bruce, K.B. (2010). On reacting to assertions and polar questions. Journal of Semantics, 27, 81-118.

15. von Fintel, K. (2003). Epistemic modals and conditionals revisited. Slides, UMass Linguistics Colloquium.

16. von Fintel, K., \& Gillies, A.S. (2010). Must . . . stay. . . strong!. Natural Language Semantics, 18, 351-383.

17. von Fintel, K., \& Heim, I. (2011). Intensional semantics. MS, MIT.

18. Franke, M., \& de Jager, T. (2011). Now that you mention it: awareness dynamics in discourse and decisions. In Benz, A., Ebert, C., Jäger, G., van Rooij, R. (Eds.) Language, games, and evolution (pp. 60-91). Berlin: Springer.

19. Gibbard, A. (1990). Wise choices apt feelings: A theory of normative judgment. Cambridge: Harvard University Press.

20. Gibbard, A. (2012). Meaning and normativity. New York: Oxford University Press.

21. Gunlogson, C. (2001). True to form: Rising and falling declaratives as questions in English. Ph.D. thesis, UC Santa Cruz.

22. Gunlogson, C. (2008). A question of commitment. Belgian Journal of Linguistics, 22, 101-136.

23. Gutzmann, D. (2015). Use-conditional meaning: Studies in multidimensional semantics. Oxford: Oxford University Press.

24. Hare, R. (1952). The language of morals. Oxford: Oxford University Press.

25. Huddleston, R., \& Pullum, G.K. (Eds.) (2002). The Cambridge grammar of the English language. Cambridge: Cambridge University Press.

26. Karttunen, L. (1972). Possible and must. In Kimball, J.P. (Ed.) Syntax and semantics 1 (pp. 1-20). New York: Academic Press.

27. Kratzer, A. (1977). What 'must' and 'can' must and can mean. Linguistics and Philosophy, 1, 337355.

28. Kratzer, A. (1981). The notional category of modality. In Eikmeyer, H.-J., \& Rieser, H. (Eds.) Words, worlds, and contexts: New approaches in word semantics (pp. 38-74). Berlin: de Gruyter.

29. Kratzer, A. (1991). Modality/Conditionals. In von Stechow, A., \& Wunderlich, D. (Eds.) Semantics: An international handbook of contemporary research (pp. 639-656). New York: de Gruyter.

30. Kratzer, A. (2012). Modals and conditionals: New and revised perspectives. New York: Oxford University Press.

31. Krifka, M. (2012). Negated polarity questions as denegations of assertions. In Kiefer, F., \& Lee, C. (Eds.) Contrastiveness and scalar implicatures. Berlin: Springer.

32. Krifka, M. (2015). Bias in commitment space semantics: Declarative questions, negated questions, and question tags. In D’Antonio, S., Moroney, M., Little, C.-R. (Eds.) Proceedings of SALT 25 (pp. 328345). Ithaca: CLC Publications. 
33. Ladd, D.R. (1981). A first look at the semantics and pragmatics of negative questions and tag questions. In Hendrik, R., Masek, C., Miller, M.F. (Eds.) Proceedings of the Chicago Linguistic Society (CLS) 17 (pp. 164-171). Chicago: CLS.

34. Lewis, D. (1981). Ordering semantics and premise semantics for counterfactuals. Journal of Philosophical Logic, 10, 217-234.

35. Lyons, J. (1977). Semantics, Vol. 2. Cambridge: Cambridge University Press.

36. Lyons, J. (1995). Linguistic semantics: An introduction. Cambridge: Cambridge University Press.

37. MacFarlane, J. (2014). Assessment sensitivity: Relative truth and its applications. Oxford: Clarendon Press.

38. Malamud, S.A., \& Stephenson, T. (2015). Three ways to avoid commitments: Declarative force modifiers in the conversational scoreboard. Journal of Semantics, 32, 275-311.

39. McCready, E. (2009). What man does. Linguistics and Philosophy, 31, 671-724.

40. Moss, S. (2018). Probabilistic knowledge. New York: Oxford University Press.

41. Murray, S.E. (2014). Varieties of update. Semantics and Pragmatics, 7, 1-53.

42. Narrog, H. (2005). Modality, mood, and change of modal meanings: A new perspective. Cognitive Linguistics, 16, 677-731.

43. Papafragou, A. (2006). Epistemic modality and truth conditions. Lingua, 116, 1688-1702.

44. Partee, B.H., \& Borschev, V. (2003). Genitives, relational nouns, and argument-modifier ambiguity. In Lang, E., Maienborn, C., Fabricius-Hansen, C. (Eds.) Modifying adjuncts (pp. 67-112). Berlin: Mouton de Gruyter.

45. Portner, P. (2007). Imperatives and modals. Natural Language Semantics, 15, 351-383.

46. Potts, C. (2005). The logic of conventional implicature. Oxford: Oxford University Press.

47. Potts, C. (2007). The expressive dimension. Theoretical Linguistics, 33, 165-197.

48. Reese, B.J. (2007). Bias in questions. Ph.D. thesis, University of Texas at Austin.

49. Repp, S. (2006). $\neg$ (A\&B). Gapping, negation and speech act operators. Research on Language and Computation, 4, 397-423.

50. Repp, S. (2009). Negation in gapping. Oxford: Oxford University Press.

51. Repp, S. (2013). Common ground management: Modal particles, illocutionary negation and VERUM. In Gutzmann, D., \& Gärtner, H.-M. (Eds.) Beyond expressives: Explorations in use-conditional meaning (pp. 231-274). Leiden: Brill.

52. Roberts, C. (1996). Information structure: Towards an integrated theory of formal pragmatics. In Yoon, J.-H., \& Kathol, A. (Eds.) OSU working papers in linguistics, Vol. 49: Papers in semantics. Columbus: The Ohio State University.

53. Roelofsen, F., \& Farkas, D.F. (2015). Polarity particle responses as a window onto the interpretation of questions and assertions. Language, 91, 359-414.

54. Romero, M. (2005). Biased yes/no questions, really, and answers. In Proceedings of the workshop on formal and computational approaches to discourse and other particles. University of Barcelona.

55. Romero, M. (2006). Biased yes/no questions: The role of VERUM. Sprache und Datenverarbeitung, $30,9-24$.

56. Romero, M. (2015). High negation in subjunctive conditionals and polar questions. In Csipak, E., \& Zeijlstra, H. (Eds.) Proceedings of Sinn und Bedeutung 19 (pp. 499-516). University of Göttingen.

57. Romero, M., \& Han, C.-h. (2004). On negative yes/no questions. Linguistics and Philosophy, 27, $609-658$.

58. van Rooy, R., \& Šafářová, M. (2003). On polar questions. In Young, R.B., \& Zhou, Y. (Eds.) Proceedings of SALT 13 (pp. 292-309). Ithaca: CLC Publications.

59. Rothschild, D. (2012). Expressing credences. Proceedings of the Aristotelian Society, 112, 99-114.

60. Sadock, J. (1971). Queclaratives. In Proceedings of the Chicago Linguistic Society (CLS) 7 (pp. 223232). Chicago: CLS.

61. Silk, A. (2013). Truth-conditions and the meanings of ethical terms. In Shafer-Landau, R. (Ed.) Oxford studies in metaethics, Vol. 8 (pp. 195-222). New York: Oxford University Press.

62. Silk, A. (2014). Accommodation and negotiation with context-sensitive expressions. Thought, 3, 115123 .

63. Silk, A. (2015). Evaluational adjectives. MS, University of Birmingham, https://goo.gl/Ocvuo7.

64. Silk, A. (2015). How to be an ethical expressivist. Philosophy and Phenomenological Research, 91, 47-81.

65. Silk, A. (2016). Discourse contextualism: A framework for contextualist semantics and pragmatics. Oxford: Oxford University Press.

66. Silk, A. (2017). How to embed an epistemic modal: Attitude problems and other defects of character. Philosophical Studies, 174, 1773-1799. 
67. Silk, A. (2017). Normative language in context. In Shafer-Landau, R. (Ed.) Oxford studies in metaethics, Vol. 12 (pp. 206-243). Oxford: Oxford University Press.

68. Silk, A. (2018). Semantics with assignment variables. MS, University of Birmingham. https://goo.gl/ kFVhw3.

69. Silk, A. (2018). Weak and strong necessity modals: On linguistic means of expressing "a primitive concept OUGHT". In Plunkett, D., \& Dunaway, B. (Eds.) Meaning, decision and norms: Themes from the work of Allan Gibbard. Ann Arbor: Michigan Publishing.

70. Simons, M. (2007). Presupposition and cooperation. MS, Carnegie Mellon University.

71. Simons, M., Tonhauser, J., Beaver, D., Roberts, C. (2010). What projects and why. In Li, N., \& Lutz, D. (Eds.) Proceedings of SALT 20 (pp. 309-327). Ithaca: CLC Publications.

72. Stalnaker, R. (1974). Pragmatic presuppositions. In Context and content: Essays on intentionality in speech and thought (pp. 47-62). Oxford: Oxford University Press.

73. Stalnaker, R. (1978). Assertion. In Context and content: Essays on intentionality in speech and thought (pp. 78-95). Oxford: Oxford University Press.

74. Stalnaker, R. (2002). Common ground. Linguistics and Philosophy, 25, 701-721.

75. Stalnaker, R. (2010). Responses to Stanley and Schlenker. Philosophical Studies, 151, 143-157.

76. Stalnaker, R. (2014). Context. New York: Oxford University Press.

77. Stephenson, T. (2007). Judge dependence, epistemic modals, and predicates of personal taste. Linguistics and Philosophy, 30, 487-525.

78. Stevenson, C. (1937). The emotive meaning of ethical terms. Mind, 46, 14-31.

79. Stone, M., \& Hardt, D. (1999). Dynamic discourse referents for tense and modals. In Bunt, H., \& Muskens, R. (Eds.) Computing meaning, Vol. 1 (pp. 301-319). Dordrecht: Kluwer.

80. Swanson, E. (2016). The application of constraint semantics to the language of subjective uncertainty. Journal of Philosophical Logic, 45, 121-146.

81. Thomason, R..H. (2002). The beliefs of other agents. MS, University of Michigan.

82. Thomason, R.H., Stone, M., DeVault, D. (2006). Enlightened update: A computational architecture for presupposition and other pragmatic phenomena. In Byron, D., Roberts, C., Schwenter, S. (Eds.) Presupposition accommodation. OSU Pragmatics Initiative.

83. Tonhauser, J., Beaver, D., Roberts, C., Simons, M. (2013). Towards a taxonomy of projective content. Language, 89, 66-109.

84. Traum, D. (1994). A computational theory of grounding in natural language conversation. Ph.D. thesis, University of Rochester.

85. Trinh, T. (2014). How to ask the obvious: A presuppositional account of evidential bias in English yes/no questions. In Crnič, L., \& Sauerland, U. (Eds.) The art and craft of semantics: A festschrift for Irene Heim (Vol. 2, pp. 227-249). Cambridge: MITWPL.

86. Truckenbrodt, H. (2006). On the semantic motivation of syntactic verb movemenet to $\mathrm{C}$ in German. Theoretical Linguistics, 32, 257-306.

87. Van Linden, A. (2012). Modal adjectives: English deontic and evaluative constructions in synchrony and diachrony. Berlin: Mouton de Gruyter.

88. Veltman, F. (1996). Defaults in update semantics. Journal of Philosophical Logic, 25, 221-261.

89. Verstraete, J.-C. (2007). Rethinking the coordinate-subordinate dichotomy: Interpersonal grammar and the analysis of adverbial clauses in English. Berlin: Mouton de Gruyter.

90. Willer, M. (2013). Dynamics of epistemic modality. Philosophical Review, 122, 45-92.

91. von Wright, G.H. (1963). Norm and action: A logical inquiry. London: Routledge and Kegan Paul.

92. Yalcin, S. (2012). Bayesian expressivism. Proceedings of the Aristotelian Society, 112, 123-160.

93. Yalcin, S. (2012). Context probabilism. In Aloni, M., Kimmelman, V., Roelofsen, F., Sassoon, G.W., Schulz, K., Westera, M. (Eds.) Proceedings of the 18th Amsterdam Colloquium (pp. 12-21). Berlin: Springer.

94. Zimmermann, M. (2011). Discourse particles. In Maienborn, C., von Heusinger, K., Portner, P. (Eds.) Semantics: An international handbook of natural language meaning (Vol. 2, pp. 2011-2038). Berlin: de Gruyter.

Publisher's Note Springer Nature remains neutral with regard to jurisdictional claims in published maps and institutional affiliations. 